\title{
Cluster Analysis of the Organic Peaks in Bulk Mass Spectra Obtained During the 2002 New England Air Quality Study with an Aerodyne Aerosol Mass Spectrometer
}

\author{
C. Marcolli ${ }^{1}$, M. R. Canagaratna ${ }^{2}$, D. R. Worsnop ${ }^{2}$, R. Bahreini ${ }^{3,4}$, J. A. de Gouw ${ }^{3,4}$, C. Warneke ${ }^{3,4}$, P. D. Goldan ${ }^{3}$, \\ W. C. Kuster ${ }^{3}$, E. J. Williams ${ }^{3,4}$, B. M. Lerner ${ }^{3,4}$, J. M. Roberts ${ }^{3}$, J. F. Meagher ${ }^{3}$, F. C. Fehsenfeld ${ }^{3}$, M. Marchewka ${ }^{5}$, \\ S. B. Bertman ${ }^{5}$, and A. M. Middlebrook ${ }^{3}$ \\ ${ }^{1}$ Institute for Atmospheric and Climate Science, ETH Zurich, Switzerland \\ ${ }^{2}$ Aerodyne Research Incorporated, Billerica, Massachusetts, USA \\ ${ }^{3}$ National Oceanic and Atmospheric Administration, Earth System Research Laboratory, Chemical Sciences Division, \\ Boulder, Colorado, USA \\ ${ }^{4}$ Cooperative Institute for Research in Environmental Sciences, University of Colorado, Boulder, Colorado, USA \\ ${ }^{5}$ Department of Chemistry, Western Michigan University, Kalamazoo, Michigan, USA
}

Received: 3 April 2006 - Published in Atmos. Chem. Phys. Discuss.: 12 June 2006

Revised: 6 December 2006 - Accepted: 6 December 2006 - Published: 19 December 2006

\begin{abstract}
We applied hierarchical cluster analysis to an Aerodyne aerosol mass spectrometer (AMS) bulk mass spectral dataset collected aboard the NOAA research vessel R. H. Brown during the 2002 New England Air Quality Study off the east coast of the United States. Emphasizing the organic peaks, the cluster analysis yielded a series of categories that are distinguishable with respect to their mass spectra and their occurrence as a function of time. The differences between the categories mainly arise from relative intensity changes rather than from the presence or absence of specific peaks. The most frequent category exhibits a strong signal at $m / z 44$ and represents oxidized organic matter probably originating from both anthropogenic as well as biogenic sources. On the basis of spectral and trace gas correlations, the second most common category with strong signals at $m / z 29,43$, and 44 contains contributions from isoprene oxidation products. The third through the fifth most common categories have peak patterns characteristic of monoterpene oxidation products and were most frequently observed when air masses from monoterpene rich regions were sampled. Taken together, the second through the fifth most common categories represent on average $17 \%$ of the total organic mass that stems likely from biogenic sources during the ship's cruise. These numbers have to be viewed as lower limits since the most common category was attributed to anthropogenic sources for this calculation. The cluster analysis was also very effective in identifying a few contaminated mass spectra that
\end{abstract}

Correspondence to: C. Marcolli

(claudia.marcolli@env.ethz.ch) were not removed during pre-processing. This study demonstrates that hierarchical clustering is a useful tool to analyze the complex patterns of the organic peaks in bulk aerosol mass spectra from a field study.

\section{Introduction}

Particles in the atmosphere play important roles in the Earth's climate and human health (Pöschl, 2005). In urban and rural locations the main components of the aerosol are often ammonium sulphate and organics (Zappoli et al., 1999). While most of the sulphate aerosol originates from anthropogenic sources, the situation is more complex for the organic component, which consists of complex mixtures of substances from different anthropogenic as well as biogenic sources. Organic particles are either emitted directly into the atmosphere by fossil fuel or biomass combustion thus forming primary organic aerosols or form from gaseous precursors leading to secondary organic aerosols (Kanakidou et al., 2005). In the aerosol phase or during cloud events the organic aerosol is still further processed (Kalberer et al., 2004; Blando and Turpin, 2000; Pöschl, 2005). Ambient measurements of their abundance, size, and chemical composition lead to an increased understanding of their sources and how they evolve in the atmosphere. Individual organic tracers can be used to apportion organic particulate matter among its sources using a chemical mass balance approach. This method involves the extraction and analysis of filter samples usually by GC/MS and is therefore limited in its time resolution as

Published by Copernicus GmbH on behalf of the European Geosciences Union. 
Table 1. Assignment of fragments for the most intense $m / z$ of the investigated mass spectra.

\begin{tabular}{ll}
\hline$m / z$ & Fragments \\
\hline 26 & $\mathrm{CN}^{+}, \mathrm{CHCH}^{+}$ \\
27 & $\mathrm{CH}_{2} \mathrm{CH}^{+}$ \\
29 & $\mathrm{CH}_{3} \mathrm{CH}_{2}^{+}, \mathrm{CHO}^{+}, \mathrm{CH}_{3} \mathrm{~N}^{+}$ \\
30 & $\mathrm{NO}^{+}, \mathrm{CH}_{2} \mathrm{O}^{+}, \mathrm{CH}_{4} \mathrm{~N}^{+}$ \\
31 & $\mathrm{CH}_{3} \mathrm{O}^{+}$ \\
41 & $\mathrm{CH}_{2} \mathrm{CHCH}_{2}^{+}$and isomers \\
42 & $\mathrm{CH}_{2} \mathrm{CH}_{2} \mathrm{CH}_{2}^{+}, \mathrm{CH}_{2} \mathrm{CO}^{+}$ \\
43 & $\mathrm{CH}_{3} \mathrm{CH}_{2} \mathrm{CH}_{2}^{+}, \mathrm{CH}_{2} \mathrm{CHO}^{+}, \mathrm{CH}_{3} \mathrm{CO}^{+}$ \\
44 & $\mathrm{CO}_{2}^{+}$ \\
55 & $\mathrm{CH}_{2} \mathrm{CHCH}_{2} \mathrm{CH}_{2}^{+}, \mathrm{CH}_{2} \mathrm{CHCO}^{+}$and isomers \\
57 & $\mathrm{CH}_{3} \mathrm{CH}_{2} \mathrm{CH}_{2} \mathrm{CH}_{2}^{+}, \mathrm{CH}_{2} \mathrm{CHCH}_{2} \mathrm{O}^{+}$ \\
& $\mathrm{CH}_{3} \mathrm{CH}_{2} \mathrm{CO}^{+}$and isomers \\
67 & $\mathrm{CH}_{2}\left(\mathrm{CH}_{3} \mathrm{CH}_{2}^{+}\right.$and others \\
69 & $\mathrm{CF}_{3}^{+}$and others \\
119 & $\mathrm{CF}_{3} \mathrm{CF}_{2}^{+}$and others \\
169 & $\mathrm{CF}_{3} \mathrm{CF}_{2} \mathrm{CF}_{2}^{+}$and others \\
\hline
\end{tabular}

well as laborious and costly (Turpin et al., 2000). An alternative to this off-line technique is offered by real-time measurements that use mass spectrometry to determine aerosol compositions (Middlebrook et al., 2003).

The Aerodyne aerosol mass spectrometer (AMS) has been designed to measure size-resolved mass distributions and total mass loadings of non-refractory chemical species from submicron particles (Jayne et al., 2000; Allan et al., 2003a; Jimenez et al., 2003). In the AMS, particles are focused into a vaporizer located within the electron impaction ionization source region of a quadrupole mass spectrometer. When it is operated in the mass spectrum mode, mass spectra from $m / z 1-300$ can be collected from several particles with good time resolution yet without particle size information. By extracting the mass spectral ion signals for various species, it has been shown to yield quantitative aerosol compositions for sulphate, nitrate, ammonium and total organic particulate matter (Allan et al., 2003b, 2004a; Bahreini et al., 2003; Schneider et al., 2004). A hierarchical clustering algorithm has been successfully applied to categorize mass spectra from individual particles measured by the Particle Analysis by Laser Mass Spectrometry (PALMS) instrument (Murphy et al., 2003). In the present study, we apply this algorithm to a quadrupole AMS dataset of particle ensembles collected during the 2002 New England Air Quality Study (NEAQS) to observe the occurrence of typical organic mass spectral features. The AMS signals in most $m / z$ channels are due to organic species; however, the exact assignment of peaks in complex mixtures such as those found in atmospheric aerosol particles is impossible. For organic substances, the AMS has been shown to generate mass spectra that are consistent with
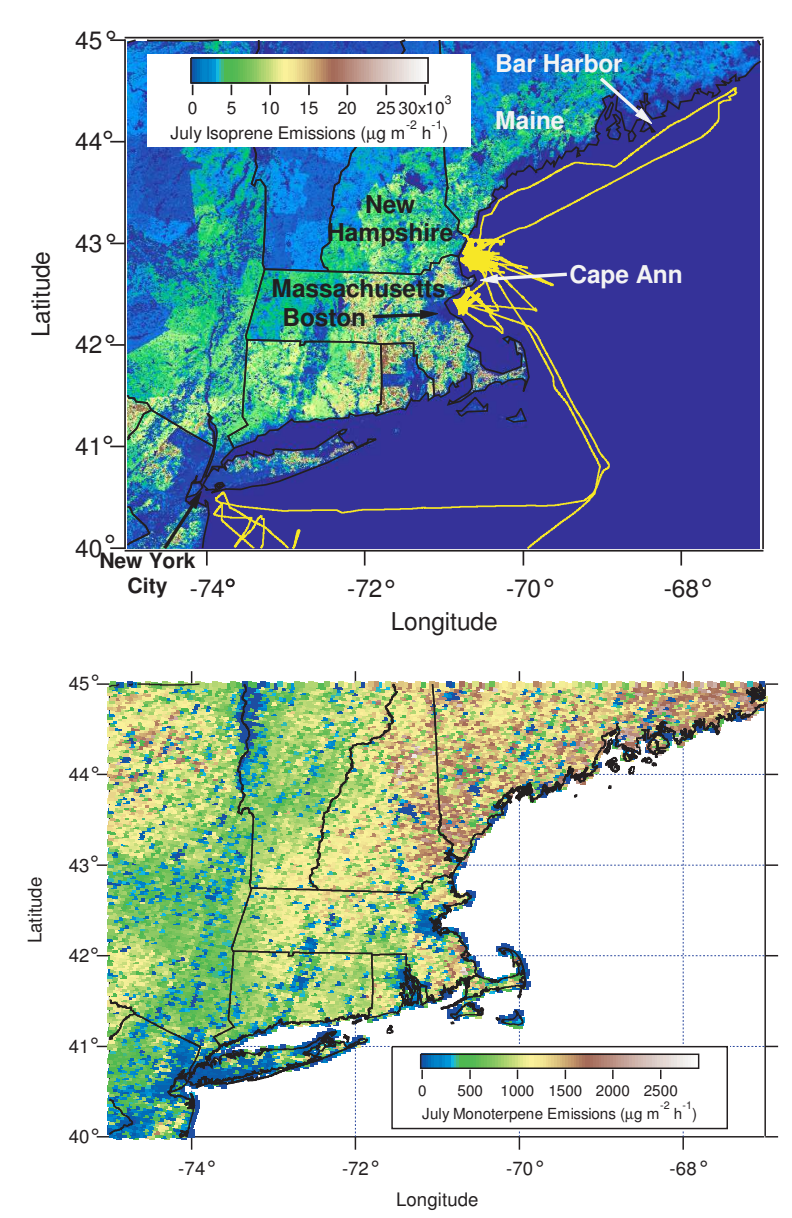

Fig. 1. Maps showing the ship track (yellow) and isoprene emissions (top panel) and monoterpene emissions (bottom panel) for the month of July from the Megan biogenic source emission profile (Guenther et al., 2006). The dark blue patch at $71^{\circ}$ longitude and $42.5^{\circ}$ latitude is the Boston urban area. The ship sailed out of Charleston, SC on 12 July 2002 (off the map) to outside New York City on 16 July. On route to the study region, an issue with the AMS sampling inlet was discovered, rendering all of the data collected up to 18 July unusable. The ship sailed into the study region on 17 July, was downwind of Boston on July 18, and then remained north of Cape Ann off the New Hampshire/Massachusetts coast until 24-26 July when it sailed up the coast of Maine past Bar Harbor. The ship was docked in New Hampshire from 26-29 July . The ship was positioned directly downwind of Boston on 31 July. From 1-5 August, the ship was off the New Hampshire coast and left the study region on 5 August. On 10 August, the ship sailed into Chesapeake Bay before heading back to Charleston and reaching the home port on 11 August (both cities are off the map).

the electron impact ionization spectra found in standard mass spectrometry libraries yet with generally more fragmentation (Allan et al., 2003b; Alfarra, 2004). Furthermore, increased fragmentation has been observed in the AMS with increased vaporizer temperature (Alfarra, 2004). Organic functional groups can be identified from the small $(m / z<50)$ 


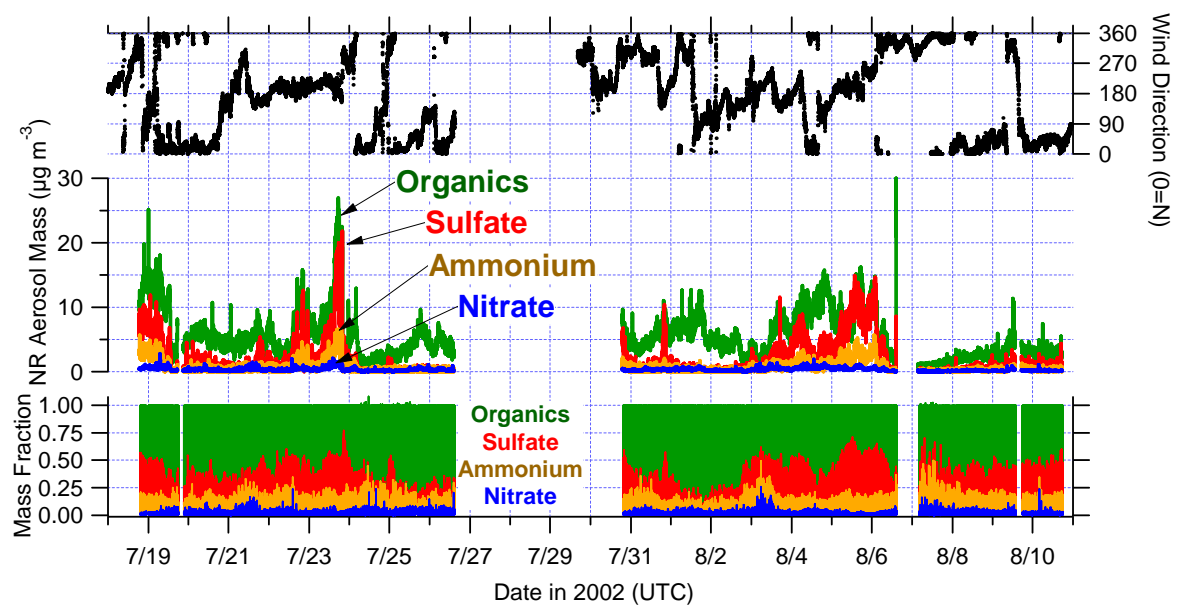

Fig. 2. Time series of the AMS non-refractory (NR) aerosol mass loadings, NR mass fraction, and wind direction.

ion fragments and information about the oxidation and saturation state of the organic aerosol fraction can be retrieved by means of the so-called ion series or delta analysis (McLafferty and Tureček, 1993; Allan et al., 2003b; Schneider et al., 2004; Bahreini et al., 2003; Alfarra et al., 2004; Canagaratna et al., 2004; Bahreini et al., 2005). However, specific patterns of the organic signals can not be captured by this method alone. Although discrimination between fragments with the same nominal $\mathrm{m} / \mathrm{z}$ such as those listed in Table 1 is now possible with a high resolution time-of-flight AMS (DeCarlo et al., 2006), several research groups have obtained low resolution data with the quadrupole AMS. The question therefore arises as to what other information about the aerosol organic material can be extracted from an AMS dataset. One method that has been used involves multivariate linear regressions, separating the ambient mass spectra into linear combinations of two (or three) components using $m / z 44$ and 57 (plus 43) as initial seeds for the deconvolution of the spectra (Zhang et al., 2005a). Scatter plots of organic peak intensities have also been used to compare ambient AMS data with reference spectra (Alfarra et al., 2006).

\section{Experimental methods}

\subsection{Sampling, analysis, and data summary}

The AMS dataset was collected aboard the NOAA research vessel Ronald H. Brown off the east coast of the United States between 18 July and 10 August 2002 as part of NEAQS 2002. A map of the ship track is shown in Fig. 1. For this study, many different types of air masses and sources were sampled (e.g., urban from Boston and New York City and biogenic from Maine) and therefore a detailed cluster analysis was performed to see whether or not specific mass spectral signatures of the several different types of general sources in the bulk mass spectra could be detected. Mass spectra from $m / z$ 1-300 and particle time-of-flight mass distributions were recorded every $2 \mathrm{~min}$ with $1 \mathrm{~min}$ sampling times in each mode for most of the study. More experimental details of the AMS dataset and how the mass loadings were measured were reported elsewhere (de Gouw et al., 2005). Volatile organic compounds (VOCs) were measured by online gas chromatography-mass spectrometry (Goldan et al., 2004) and proton-transfer-reaction mass spectrometry (de Gouw et al., 2003), and ozone measurements were obtained using a commercial UV absorbance instrument (Thermo Environmental Instruments Inc., Model 49C).

The AMS non-refractory mass loadings for organic material, sulphate, ammonium, and nitrate are shown in Fig. 2 along with the wind direction during sampling. As previously reported, the overall submicron aerosol composition during this study was predominantly organic and sulphate (Quinn and Bates, 2003; Bates et al., 2005). The highest loadings of both sulphate and organic mass occurred when the wind direction was from the southwest where the air masses had recently come from urban sources. Classification of the synoptic weather in New England shows that transport from the west, southwest, and south results in hot, humid conditions (Atlantic Return) and the highest fine particle concentrations (Slater et al., 2002; Keim et al., 2005). The AMS non-refractory aerosol mass loadings were significantly lower and dominated by organic material when the winds were from the north where monoterpene emissions were prevalent (see Fig. 1). Low fine particle concentrations with more organic carbon relative to sulphate than in the southwesterly winds are common in the region when the transport is from the northwest, north, and northeast with cold, dry conditions (Canadian High) (Slater et al., 2002; Keim et al., 2005). Hence, grouping the AMS dataset by wind direction is reasonably representative of these two weather conditions. 
2.2 Derived quantities: photochemical age and delta analysis

In this manuscript we will make use of the photochemical age of an air mass, an isoprene source term, and a delta analysis of the AMS mass spectra. The photochemical age of the air masses was determined from the VOCs by examining the ratios of toluene to benzene, and the amount of isoprene from the source was extrapolated from the ratio of methyl vinyl ketone (MVK) plus methacrolein (MACR) to isoprene (see Eqs. 1, 2a, and 2b in de Gouw et al., 2005). For the delta analysis, each $m / z$ in the spectrum corresponds to a delta value equal to $m / z-14 \mathrm{n}+1$ where $\mathrm{n}$ is an integer (McLafferty and Tureček, 1993). The delta value of a particular $m / z$ provides an indication of the functionality, given that hydrocarbons typically differ by a $\mathrm{CH}_{2}$ group which is $14 \mathrm{amu}$, with negative delta values generally indicating unsaturated hydrocarbons and positive delta values generally indicating oxidized hydrocarbons. The intensity-weighted averages of the delta values are then calculated for various ranges of carbon number (Bahreini et al., 2005).

\subsection{Hierarchical cluster analysis}

The hierarchical clustering algorithm that was developed for PALMS (Particle Analysis by Laser Mass Spectrometry) data (Murphy et al., 2003) is briefly described here. The most similar spectra or clusters are sequentially combined until a stopping condition is met. The algorithm uses the dot product between mass spectra as the similarity criterion: the most similar spectra or clusters are assigned the same category and their mass spectra are averaged. Mathematically, the total signal in each spectrum is normalized to unit intensity by dividing the peak intensities by the square root of the sum of the squares of the individual peak intensities and then each spectrum is represented as a vector:

$\boldsymbol{A}=\left[a_{1}, a_{2}, a_{3}\right.$, etc. $]$

where $\mathrm{a}_{1}, \mathrm{a}_{2}, \mathrm{a}_{3}$, etc. are the normalized peak intensities at various $m / z$. The dot product of two normalized vectors, $\boldsymbol{A}$ and $\boldsymbol{B}$, is simply:

$$
\boldsymbol{A} \cdot \boldsymbol{B}=a_{1} b_{1}+a_{2} b_{2}+a_{3} b_{3}+\text { etc. }
$$

This dot product is the cosine of the angle between the two vectors: if it is zero the normalized spectra are orthogonal and if it is one the normalized spectra are identical. In hierarchical clustering, the data are searched for the pair of spectra with the highest dot product. Those two spectra are averaged and renormalized to produce a category that replaces them. Then the dataset, now smaller by one spectrum, is again searched for the highest dot product, whether it is between two spectra or a spectrum and a category. These are averaged and the process is continued until all the remaining dot products are less than a stopping condition (strict criterion). The number of spectra in each category is retained to obtain a weighted average when subsequent spectra are included. For categories containing a small number of spectra, the stopping condition is loosened (loose criterion) to allow less-closely matched spectra to be combined in small categories. At the end of clustering, a final pass is made to ensure all of the spectra are placed in the appropriate category, which reduces the bias of the sequence for combining.

The PALMS hierarchical clustering algorithm was adapted to the AMS mass spectra. Spectra obtained during the field study from ammonium nitrate calibration particles or that were known to contain contaminants were initially removed, resulting in 12730 spectra for the cluster analysis. The peaks known to be dominated by air or by inorganic ions $(\mathrm{m} / \mathrm{z}, 14$ $24,28,32-34,36,39,40,47-50,64-66,80-83,98-100)$ were excluded and the peaks at $m / z 29,30,38$, and 44 were corrected for contributions from air using the method of $\mathrm{Al}$ lan et al. (2004a). Although $\mathrm{m} / \mathrm{z} 38$ and 41 can originate from inorganic species (specifically $\mathrm{H}^{37} \mathrm{Cl}^{+}$and ${ }^{41} \mathrm{~K}^{+}$, respectively), they were not excluded in this analysis. The average noise levels as determined by the method described by Allan et al. (2003a) have been subtracted from the peak signals at each $m / z$ and any negative values were set to zero. This was done to give the channels with high noise level and low signal less weight. Although there could be a bias due to this procedure, it would occur mainly in the high $m / z$ peaks where the signals were small and does not significantly impact the cluster analysis using linear signals. Finally, the total signal of each spectrum was normalized to unit intensity. In the application for the PALMS datasets, a combination of the linear scaled peak intensities and the log scaled raw spectrum was used. For the present work, only the linear peak intensities were used. Using the log of the signals intensified the noise level of the high $\mathrm{m} / \mathrm{z}$ peaks and did not contain useful information since most of the spectral signal was in the smaller ion fragments. The diversity (or number of categories) and the relative occurrence of the categories for approximately every two hours were calculated by forming groups of sixty of the $2 \mathrm{~min}$ averaged spectra as a function of time.

\section{Results and discussion}

\subsection{Categorization}

The AMS mass spectra in this study were from ambient atmospheric aerosols, which are composed of numerous organic compounds with varying concentrations rather than a few individual organic species. Thus, these data did not form distinct clusters per se, and the choice of the stopping condition and the number of resulting categories was arbitrary. For our dataset, the 12730 spectra were first divided into four subsets by time. To reduce computing time, the clustering algorithm was run separately for each subset with strict criteria until the number of categories was low enough to be easily 


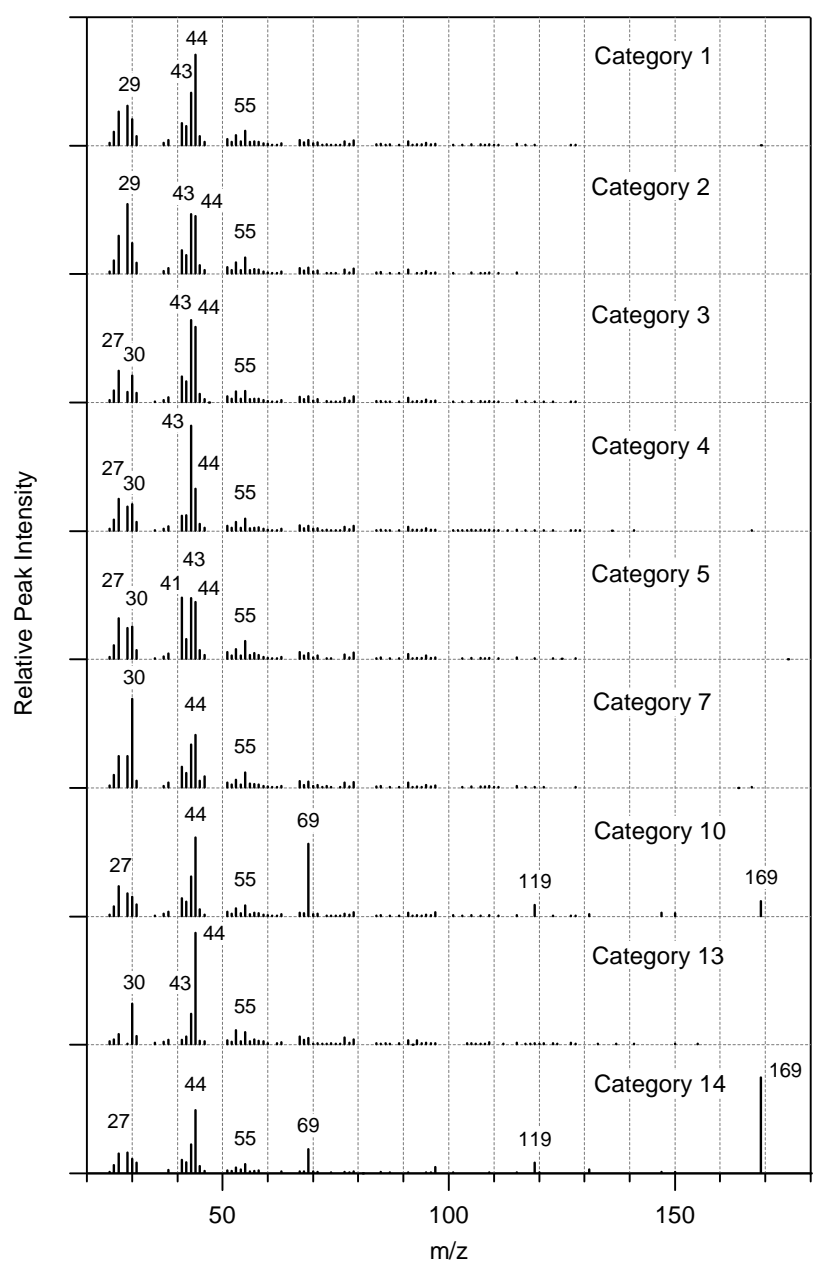

Fig. 3. Relative peak intensities (linear arbitrary units) for the top 5 and other prominent categories.

handled in one set for the last pass. The stopping condition for the last pass was optimized to yield clusters with different spectral features as well as distinct time sequences. The criteria for each pass and the resulting number of categories are shown in Table 2. After the categories were established, a final pass of all the spectra was performed to ensure that they were placed in the appropriate categories. We stopped with 48 categories - the largest one comprising 9505 of the total of 12730 spectra, the smallest ones containing one spectrum each. Table 3 lists the most prominent peaks in the top 15 categories and the averaged mass spectra of some important categories are shown in Fig. 3. The top 5 categories comprise over $92 \%$ of the spectra. The categories mainly differ in the relative intensity rather than in the presence or absence of specific peaks. Most of them are dominated by peaks with $m / z$ below 50 . Thus, the sampled organic aerosol fraction either consisted of quite small molecules or strongly fragmented in the mass spectrometer. The Aerodyne mass spectra collected during the MINOS campaign by Schnei-
Table 2. Criteria used for generating clusters.

\begin{tabular}{lllll}
\hline $\begin{array}{l}\text { Pass } \\
\text { No. }\end{array}$ & $\begin{array}{l}\text { Strict } \\
\text { Criterion }\end{array}$ & $\begin{array}{l}\text { Loose } \\
\text { Criterion }\end{array}$ & $\begin{array}{l}\text { No. Spectra for } \\
\text { Loose } \\
\text { Criterion }\end{array}$ & $\begin{array}{l}\text { Resulting } \\
\text { No. } \\
\text { Categories }\end{array}$ \\
\hline 1 & 0.97 & 0.97 & - & 4120 \\
2 & 0.97 & 0.97 & - & 2233 \\
3 & 0.97 & 0.97 & - & 1715 \\
4 & 0.93 & 0.77 & 50 & 48 \\
\hline
\end{tabular}

der et al. (2004) also show a strong dominance of low $\mathrm{m} / \mathrm{z}$ peaks whereas around $40 \%$ of the total organic signal during the ACE-Asia campaign was due to fragments with $\mathrm{m} / \mathrm{z}$ above 50 (Bahreini et al., 2003). The individual spectra are assigned to the category which gives the best match based on the dot product as the similarity criterion. While still meeting the criterion, the sequence of most intense peaks for individual category members can deviate from the one of the averaged spectrum: $8 \%$ of category 1 spectra exhibit the strongest signal at $m / z 43$ instead of $m / z 44$ as the average in Fig. 3 shows; in category $2,46 \%$ of the spectra show $m / z 29$ as the strongest peak, $31 \% \mathrm{~m} / z 43$, and $19 \% \mathrm{~m} / z$ 44, reflecting the similar intensities of $m / z 29,43$, and 44 in the averaged spectrum.

Some of the most abundant peaks can be unambiguously assigned to specific organic fragments as shown in Table 1 . Mass $m / z 44$ is a sign of oxidized organic species since it is due to $\mathrm{CO}_{2}^{+}$e.g. from oxo- and dicarboxylic acids as well as highly oxygenated species (Alfarra, 2004). It is strong in category 1 (Fig. 3), thus, this category can be considered as highly oxidized. Although they could arise from ammonium or sodium nitrate, $\mathrm{m} / \mathrm{z} 30$ and 46 were included in this analysis since they could also be due to $\mathrm{NO}^{+}$and $\mathrm{NO}_{2}^{+}$from organic nitrates, nitro aromatics, and possibly other organonitrogen or organo-oxygen containing species. Mass $m / z 30$ is the most abundant peak in category 7 (Fig. 3), the second most abundant peak in category 13 , and is common in many other categories (Table 3). The peaks at $m / z 69,119$, and 169 have been observed in fluorinated hydrocarbon oil from mechanical pumps (J. Jimenez and P. Silva, personal communication). Mass $m / z 69$ and 169 are the second most and the most abundant ones in categories 10 (with 60 spectra) and 14 (with 24 spectra), respectively (Fig. 3).

In many of the categories, $m / z 57$ is typically not a major peak. A strong peak at $m / z 57$ along with $m / z 55$ and other hydrocarbon fragments differing from these two masses in steps of 14 amu due to $\mathrm{CH}_{2}$ groups have been found in the AMS spectra from direct emissions of diesel exhaust (Canagaratna et al., 2004) and this distinct pattern has been observed in urban mass spectra during the morning (Allan et al., 2003b; Alfarra et al., 2004; Zhang et al., 2005a,b). During the NEAQS 2002 study, however, the only time when a relatively high $m / z 57$ was observed was when the ship's 
Table 3. Characteristics of the 15 most abundant categories.

\begin{tabular}{lll}
\hline Category & No. spectra & Most intense $m / z$ (intensities normalized to the largest peak \pm standard deviation) \\
\hline 1 & 9505 & $44(100 \pm 15), 43(58 \pm 16), 29(44 \pm 16), 27(38 \pm 11), 30(29 \pm 11), 41(25 \pm 12), 42(22 \pm 8), 55(16 \pm 9)$ \\
2 & 1052 & $29(100 \pm 16), 43(86 \pm 20), 44(83 \pm 22), 27(55 \pm 16), 30(44 \pm 18), 41(34 \pm 17), 42(27 \pm 11), 55(24 \pm 13)$ \\
3 & 513 & $43(100 \pm 14), 44(92 \pm 16), 27(39 \pm 15), 30(33 \pm 15), 41(32 \pm 18), 42(26 \pm 15), 26(15 \pm 9), 55(14 \pm 11)$ \\
4 & 414 & $43(100 \pm 11), 44(40 \pm 18), 27(31 \pm 13), 30(25 \pm 12), 29(23 \pm 16), 42(15 \pm 10), 41(14 \pm 12), 55(12 \pm 11)$ \\
5 & 275 & $41(100 \pm 22), 43(99 \pm 27), 44(93 \pm 31), 27(67 \pm 23), 30(53 \pm 23), 29(51 \pm 26), 42(33 \pm 16), 55(30 \pm 20)$ \\
6 & 259 & $44(100 \pm 22), 27(71 \pm 17), 43(54 \pm 20), 30(50 \pm 20), 55(32 \pm 19), 42(25 \pm 16), 26(20 \pm 13), 53(15 \pm 12)$ \\
7 & 163 & $30(100 \pm 15), 44(60 \pm 22), 43(49 \pm 18), 27(36 \pm 13), 29(36 \pm 19), 41(24 \pm 15), 55(17 \pm 11), 42(17 \pm 10)$ \\
8 & 137 & $27(100 \pm 19), 43(74 \pm 22), 44(62 \pm 21), 30(37 \pm 17), 29(31 \pm 21), 42(23 \pm 15), 41(22 \pm 17), 26(17 \pm 13)$ \\
9 & 82 & $29(100 \pm 16), 44(49 \pm 24), 27(29 \pm 16), 30(26 \pm 13), 43(23 \pm 14), 42(15 \pm 10), 41(13 \pm 12), 26(13 \pm 10)$ \\
10 & 60 & $44(100 \pm 23), 69(92 \pm 27), 43(50 \pm 22), 27(38 \pm 15), 29(29 \pm 17), 30(25 \pm 12), 41(23 \pm 18), 169(19 \pm 20)$ \\
11 & 53 & $43(100 \pm 20), 27(78 \pm 17), 30(52 \pm 21), 55(29 \pm 22), 31(22 \pm 13), 42(21 \pm 15), 41(20 \pm 18), 26(18 \pm 15)$ \\
12 & 38 & $55(100 \pm 21), 44(57 \pm 22), 43(45 \pm 18), 29(32 \pm 17), 27(30 \pm 15), 30(24 \pm 11), 42(15 \pm 8), 41(14 \pm 12)$ \\
13 & 25 & $44(100 \pm 16), 30(37 \pm 15), 43(28 \pm 17), 53(13 \pm 9), 55(11 \pm 11), 27(9 \pm 8), 31(8 \pm 9), 67(7 \pm 8)$ \\
14 & 24 & $169(100 \pm 20), 44(66 \pm 21), 43(30 \pm 11), 69(25 \pm 16), 29(22 \pm 17), 27(21 \pm 8), 30(15 \pm 6), 41(14 \pm 11)$ \\
15 & 15 & $57(100 \pm 18), 44(44 \pm 18), 43(40 \pm 16), 30(25 \pm 13), 29(23 \pm 14), 27(22 \pm 6), 41(20 \pm 9), 42(12 \pm 6)$ \\
\hline
\end{tabular}

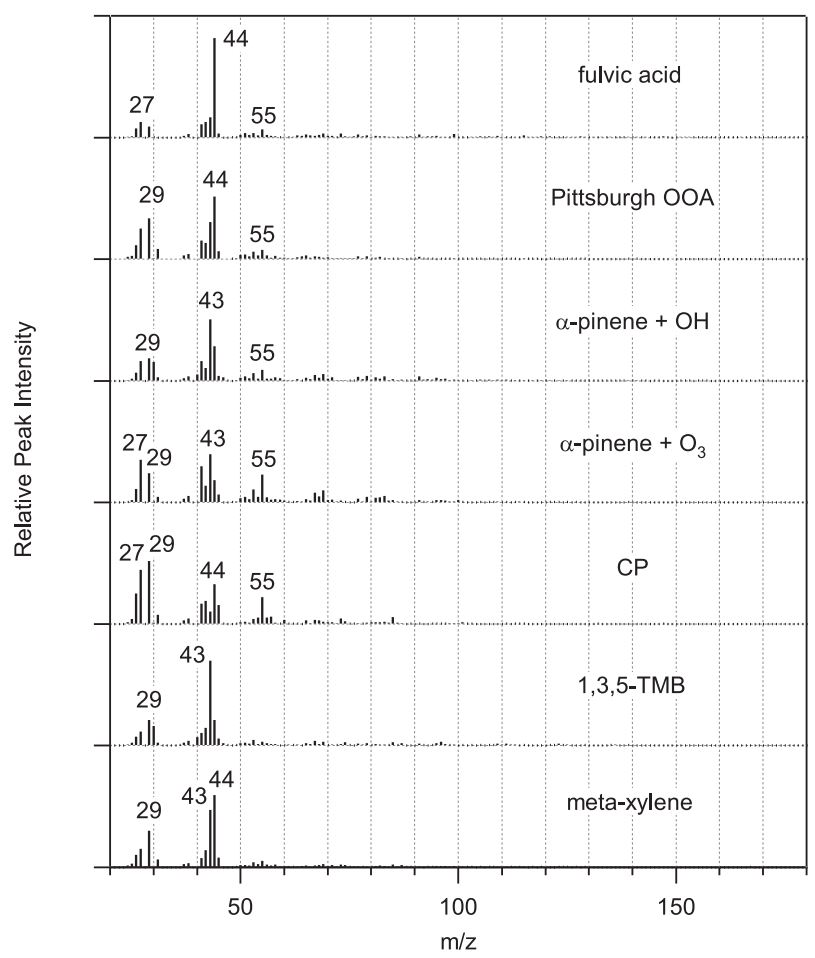

Fig. 4a. Reference spectra (linear arbitrary units): laboratory generated spectra of fulvic acid (Alfarra et al., 2006), Pittsburgh oxidized organic aerosol (OOA) from a field study (Zhang et al., 2005a), the aerosol oxidation products of $\alpha$-pinene plus $\mathrm{OH}$ (Alfarra et al., 2006) and plus ozone $\left(\mathrm{O}_{3}\right)$ (Bahreini et al., 2005), cyclopentene (CP) plus $\mathrm{O}_{3}$ (Bahreini et al., 2005), 1,3,5-trimethylbenzene (TMB) plus $\mathrm{OH}$ (Alfarra et al., 2006), and meta-xylene plus OH (Bahreini et al., 2005).

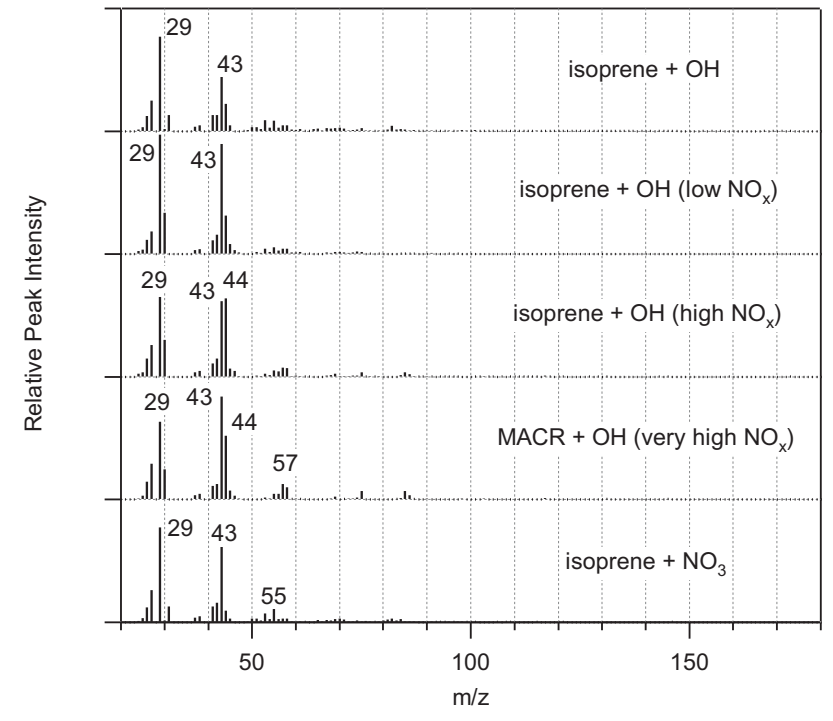

Fig. 4b. Reference spectra (linear arbitrary units): laboratory generated spectra of the aerosol oxidation products of isoprene plus hydroxyl radical $(\mathrm{OH})$ (unpublished data from R. Bahreini), isoprene plus $\mathrm{OH}$ with varying levels of nitrogen oxides $\left(\mathrm{NO}_{x}\right)$ (Kroll et al., 2006), methacrolein (MACR) plus $\mathrm{OH}$ with very high $\mathrm{NO}_{x}$ (Kroll et al., 2006), and isoprene plus nitrate radical $\left(\mathrm{NO}_{3}\right)$ (work in progress from $\mathrm{S}$. Murphy). Low $\mathrm{NO}_{x}$ was less than $1 \mathrm{ppbv}$, high $\mathrm{NO}_{x}$ was 400 ppbv, and very high $\mathrm{NO}_{x}$ was 800 ppbv.

exhaust was inadvertently sampled while changing position, and these spectra were removed from the cluster analysis during pre-processing. The lack of fresh organic aerosol spectra during this study is consistent with the VOC data which nearly always exhibited some degree of aging (de Gouw et al., 2005). The hydrocarbon-like fraction described by 
Zhang et al. (2005a) might have been too dilute or highly processed to yield a specific signal in the mass spectra. Category 15 with 15 spectra was the only one with strong $m / z 57$ (Table 3).

\subsection{Comparison with mass spectra}

Very recently, mass spectra of secondary organic aerosols formed from the oxidation of anthropogenic and biogenic precursors have been measured by different research groups with the quadrupole AMS (Alfarra et al., 2006; Bahreini et al., 2005). Secondary organic aerosol has also recently been observed in chamber studies of isoprene oxidation (Kroll et al., 2005, 2006), and AMS mass spectra of these particles have been obtained in similar experiments (unpublished data from R. Bahreini and work in progress from S. Murphy). Note that methacrolein (MACR) is an oxidation product of isoprene. The laboratory spectra are shown in Fig. 4 together with reference spectra for fulvic acid (Alfarra et al., 2006) and oxidized urban aerosol derived from a multivariate linear regression of the aerosol sampled in Pittsburgh in September 2002 (Pittsburgh OOA) (Zhang et al., 2005a). These spectra are compared to the top 5 categories to find similarities and their correlations are shown in Fig. 5. Since aerosols from different sources may have been sampled at the same time by the AMS spectrometer during the field study, the measured mass spectra might be dominated by one type of aerosol or contain a mixture of aerosol types. Because of its abundance throughout the whole campaign, category 1 spectral features are the most likely to be mixed into other categories resulting in a relatively large $m / z 44$ signal. Furthermore, other peaks in the spectra may form distinct patterns in the absence of $m / z 44$. Therefore, the correlations were carried out with and without $m / z 44$. The complete set of peaks used for these correlations are at $m / z 12,13,25,26,27,29,31,37,38,41$, $42,43,44,45,51,53,55,57,67,69,71,73,85,87,89$, and 91 , which have the most signal intensity.

The best correlations of category 1 occur with the spectrum of oxidized organic aerosols obtained in Pittsburgh, which become distinctly better than the ones with metaxylene when $m / z 44$ is excluded (Fig. 5a). Therefore, category 1 can be considered as highly oxidized. The patterns observed in categories 2-5 are quite similar to spectra obtained from oxidation of mostly biogenic precursors (Alfarra et al., 2006; Bahreini et al., 2005; Kroll et al., 2006) and these particles are less oxidized than when $\mathrm{m} / \mathrm{z} 44$ dominates the spectrum (Alfarra, 2004). The category 2 spectrum has a large peak at $m / z 29$, similar signal intensities at $m / z 43$, and $m / z 44$ and relatively low signal at $m / z 41$, $m / z 55$, and $m / z 57$ which signifies the prevalence of carbonyls $(\mathrm{C}=\mathrm{O})$ from either ketones, aldehydes, and carboxylic acids (McLafferty and Tureček, 1993; Alfarra et al., 2004). This category shows the highest correlation with the isoprene oxidation spectra (Fig. 5b). Category 3 most closely resembles the spectrum observed of aerosols produced by $\alpha$ - pinene oxidation with hydroxyl radical $(\mathrm{OH})$ (Alfarra et al., 2006), especially when $m / z 44$ is excluded (Fig. 5c). Hence, it could be characteristic of more strongly oxidized products than present in the reference. Category 4 is extremely similar to the spectra formed by $\mathrm{OH}$ oxidation of $\alpha$-pinene or 1,3,5trimethylbenzene (TMB) (Alfarra et al., 2006) (Fig. 5d) and the pattern of the main peaks of category 5 has the highest resemblance to the one formed during $\alpha$-pinene ozonolysis experiments (Bahreini et al., 2005) (Fig. 5e). A list of dot products using all of the peaks and calculated in the same way as for the clustering program is presented in Table 4 . These results are similar to those from the linear regression correlations: category 1 is closest to the Pittsburgh OOA and meta-xylene, category 2 is closest to the isoprene plus $\mathrm{OH}$ under high $\mathrm{NO}_{x}$ conditions and methacrolein (MACR) plus $\mathrm{OH}$ under very high $\mathrm{NO}_{x}$ conditions, category 3 is closest to $\alpha$-pinene plus $\mathrm{OH}$, category 4 is closest to $\alpha$-pinene plus $\mathrm{OH}$ and TMB, and category 5 is closest to both $\alpha$-pinene oxidation products. If the clustering algorithm was used to put the reference spectra into categories, OOA and meta-xylene would have been placed in category 1 , isoprene plus $\mathrm{OH}$ under high $\mathrm{NO}_{x}$ conditions and methacrolein (MACR) plus $\mathrm{OH}$ under very high $\mathrm{NO}_{x}$ conditions in category 2 , and $\alpha$-pinene plus $\mathrm{OH}$ and TMB would have been placed in category 4 . All of the other reference spectra would not have been placed in the top 5 categories when applying the strict criterion.

In addition to subtle differences in the mass spectra of the low $m / z$ peaks from various precursors, the high $m / z$ fragments may also exhibit distinct mass spectral patterns. These can be analyzed by the ion series or delta analysis technique which uses the delta value, $\Delta=m / z-14 n+1$ (where $n$ is the "nominal" number of $\mathrm{CH}_{2}$ groups), as an indication of the functional groups in the molecule. Bahreini et al. (2005) previously used this technique to examine the delta patterns of oxidation products from many types of precursors (terpenoid, cycloalkene, and meta-xylene). In that study, the larger carbon fragments (C5-C6 and C7-C15) of secondary organic aerosols from different biogenic (terpenoid) precursors showed negative delta values which was in sharp contrast to the positive ones observed for secondary organic aerosols formed from cycloalkenes and meta-xylene representing anthropogenic precursors.

The average delta patterns for the top 5 categories (Fig. 6) are similar to each other and more similar to those from biogenic precursors than those from anthropogenic precursors, implying that the organic mass of higher $\mathrm{m} / \mathrm{z}$ fragments in these categories is biogenic in origin. Note that $23 \%$ of the total organic signal is represented by these peaks. Indeed all of the top 15 categories, with the exception of category 14 , have comparable average delta patterns. The delta pattern of category 5 is nearly identical to that from $\alpha$-pinene ozonolysis products (Bahreini et al., 2005) which strongly indicates that secondary organic aerosol from $\alpha$-pinene ozonolysis was present in these spectra. However it must be noted that the delta patterns for the aerosol products of only one aromatic 
Table 4. Dot products of the reference spectra with the top 5 categories. The bold values indicate the reference spectra that have the highest dot products for each category spectrum.

\begin{tabular}{llllll}
\hline & Category 1 & Category 2 & Category 3 & Category 4 & Category 5 \\
\hline Fulvic Acid & 0.89 & 0.69 & 0.80 & 0.58 & 0.70 \\
Pittsburgh OOA & $\mathbf{0 . 9 6}$ & 0.93 & 0.87 & 0.79 & 0.87 \\
Isoprene $+\mathrm{OH}$ & 0.75 & 0.91 & 0.65 & 0.73 & 0.73 \\
Isoprene $+\mathrm{NO}_{3}$ & 0.69 & 0.87 & 0.65 & 0.78 & 0.71 \\
Isoprene $+\mathrm{OH}\left(\right.$ low $\left.\mathrm{NO}_{x}\right)$ & 0.76 & 0.91 & 0.72 & 0.84 & 0.75 \\
Isoprene $+\mathrm{OH}\left(\right.$ high $\left.\mathrm{NO}_{x}\right)$ & 0.93 & $\mathbf{0 . 9 7}$ & 0.86 & 0.86 & 0.85 \\
Methacrolein $+\mathrm{OH}\left(\right.$ very high $\left.\mathrm{NO}_{x}\right)$ & 0.88 & 0.95 & 0.87 & 0.92 & 0.84 \\
$\alpha$-Pinene $+\mathrm{OH}$ & 0.90 & 0.92 & $\mathbf{0 . 9 6}$ & $\mathbf{0 . 9 8}$ & $\mathbf{0 . 9 3}$ \\
$\alpha$-Pinene $+\mathrm{O}_{3}$ & 0.80 & 0.86 & 0.81 & 0.83 & 0.91 \\
$\mathrm{CP}$ & 0.78 & 0.85 & 0.62 & 0.58 & 0.75 \\
TMB & 0.78 & 0.84 & 0.89 & $\mathbf{0 . 9 8}$ & 0.82 \\
Meta-xylene & 0.95 & 0.90 & 0.91 & 0.85 & 0.83 \\
\hline
\end{tabular}

anthropogenic precursor compound (meta-xylene) have been investigated (Bahreini et al., 2005).

\subsection{Trends with time and wind direction}

To judge whether the categories are related to certain time periods, we investigated them as a function of time (Fig. 7). The top two panels show the organic mass loadings and the diversity of the organic aerosol fraction over the whole measurement period. It can be seen that the diversity - i.e. the number of different categories within groups of 60 consecutive measurements - is highest at times when the overall mass loading is lowest. Since category 1 comprises $75 \%$ of the spectra, there is a very strong anti-correlation between the diversity and this category. The high diversity at low mass loadings might be to some extent a statistical effect, since for averaging times of $1 \mathrm{~min}$ and at low mass loadings only few particles are responsible for the detected signal at a specific $m / z$ channel and the presence of one large particle might influence the resulting mass spectrum (Bahreini et al., 2003). Since also at low mass loadings some time periods are strongly dominated by category 1 , the diversity can not be completely explained by counting statistics. The low diversity for high mass loadings may indeed be an indication that the air masses are homogeneous and well-mixed.

Category 1 was dominant during almost the whole measurement period, being most abundant at times when the organic mass loading was high. Its incidence dropped notably during three periods: on 23 July, 3 August, and 6 August (Fig. 7). In all three instances, the organic mass loadings were much lower, due to either the passage of cold fronts or major wind direction shifts from the southeast to the southwest or north in a westerly fashion (Fig. 2). Although the contribution to any wind direction is dominated by category 1 spectra, the relative contribution for category 1 spectra is the highest when the winds are from the east or south (Fig. 8).
Category 2 is prevalent on 23-24 July, 3 August, and 56 August during wind shifts at the end of the high organic mass events and is highest on August 5 when categories 3 through 5 are altogether absent. During these time periods the winds are from the southwest (Figs. 2 and 8) and have passed over the Boston urban area as well as an isoprene "hot spot" (Fig. 1a). This further supports the notion of category 2 as being indicative of isoprene oxidation products which might be mixed together with oxidized urban aerosol as established from the correlations in Fig. 5b. Categories 3 through 5 are most common mainly during two time periods (24-26 July and 6-7 August) when the organic mass loading was relatively low and winds are from the north (Figs. 2 and 8). Because northerly winds come from over Canada with relatively low isoprene and high monoterpene emissions (Fig. 1), the incidence of categories 3 through 5 supports the interpretation of these categories as originating from monoterpene oxidation products. Although categories 7 and 13 both have relatively large peaks at $\mathrm{m} / z 30$, their time trends are different: Category 7 was observed mainly on three days - 21 July, 3 August, and 7 August - whereas category 13 was observed mainly on 7 August, the day with the lowest submicron aerosol mass throughout the whole campaign. Categories 10 and 14 occurred mainly on 10 August between 03:00 and 16:00 UTC, when the ship was in Chesapeake Bay. The ship's movement during this time did not create sufficient relative wind off the bow to sample air away from the ship. The clear signature of fluorocarbons in categories 10 and 14 indicates that the AMS sampled mechanical pump exhaust from other sampling equipment on the ship.

Other top 15 categories $(6,8,9$, and 11 , not shown in Figs. 3 or 7) were observed most frequently during low mass periods when the spectra showed a large variation of composition as is reflected by the high diversity (Fig. 7b). They contain between 53 and 259 spectra and exhibit the main peak at $m / z 27$ (category 8), $m / z 29$ (category 9), and $m / z, 43$ 

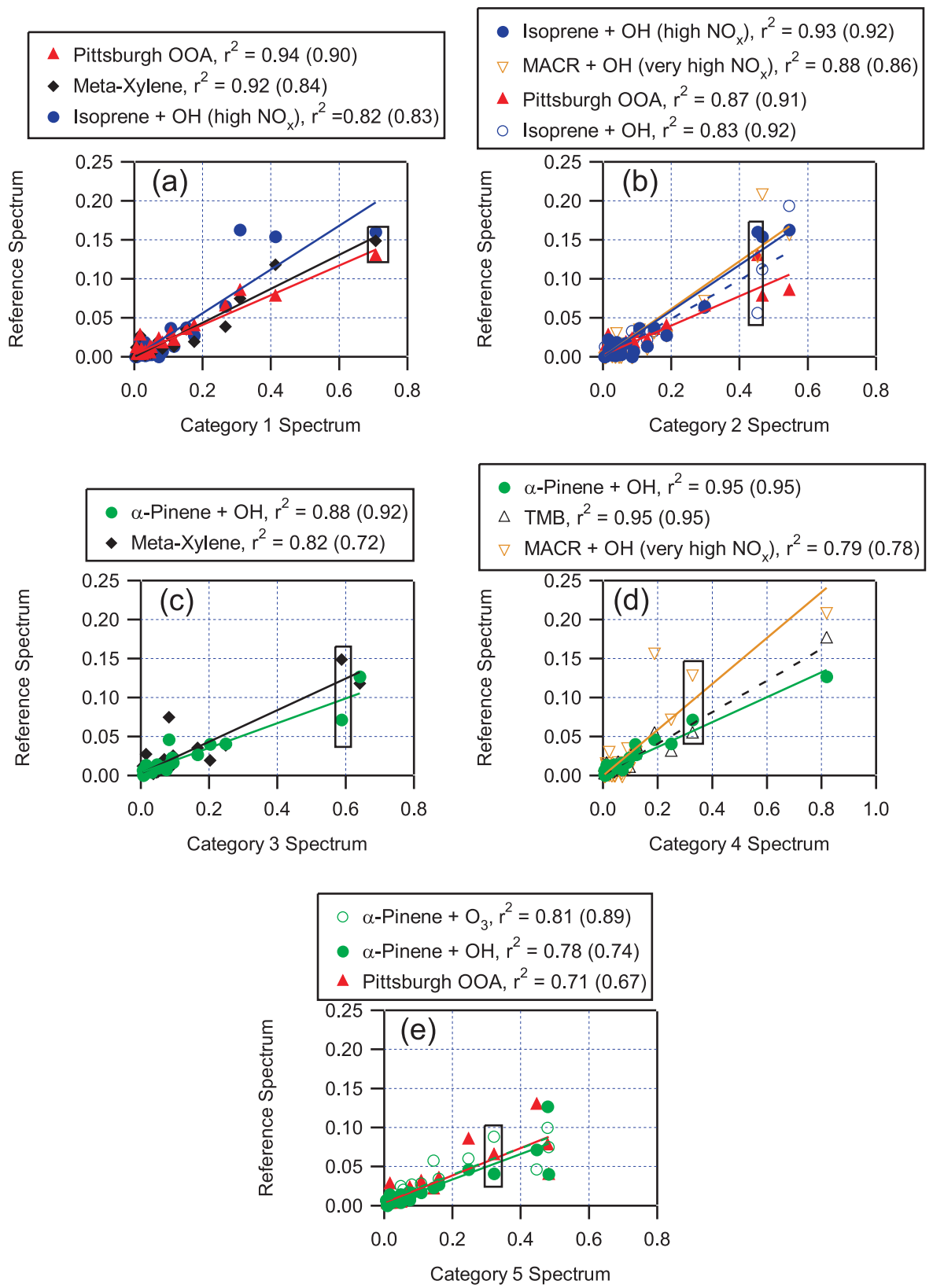

Fig. 5. Correlation plots of the peaks (arbitrary units) in the reference spectra (Fig. 4) with the peaks (arbitrary units) in categories $1-5$ (Fig. 3). Note only the reference spectra with the highest correlation coefficients are shown. The correlation coefficients in parentheses are for correlations without $m / z 44$ (points in the box).

(category 11), indicating a low degree of oxidation at these low mass periods. The exception is category 6 which has a large peak at $m / z 44$. Category 11 with hardly any signal at $\mathrm{m} / \mathrm{z} 44$ was only present when the organic mass was below $4 \mu \mathrm{g} / \mathrm{m}^{3}$.

\subsection{Diurnal and photochemical age trends}

The diurnal cycles of the total organic mass loading, ozone, and the shortwave radiation averaged over the whole sam- pling period as well as the average relative occurrence of the top 5 categories are shown in Fig. 9. Although spectra were averaged that were collected at different locations and under varying weather conditions, it still allows for summarizing general trends: The particulate organic matter exhibits the highest values from 14:00 to 18:00 UTC (10:00 to 14:00 local time) when the solar radiation was at a maximum during the afternoon. This is consistent with secondary organic aerosol formation by gas-to-particle conversion that 


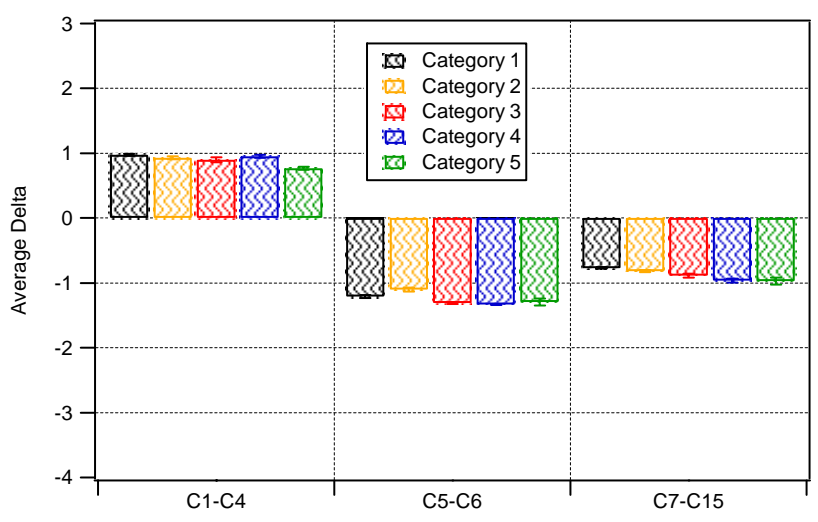

Fig. 6. Average delta patterns (arbitrary units) for low (C1-C4), mid (C5-C6), and high (C7-C15) $\mathrm{m} / z$ peaks for categories 1 through 5.

contributed to the total particulate organic mass. Category 1 exhibits a similar diurnal cycle, but with a wider maximum. Therefore, gas-to-particle conversion may only partly explain the diurnal cycle of category 1, indicating that further processing might take place within the particles. Another possibility is the change in composition to more oxidized particles from the free troposphere as the nocturnal boundary layer collapses. The diurnal pattern of ozone is similar to that from organic aerosol mass and even more similar to that of category 1 , which suggests that they are both from photochemical production rather than transport. Category 2 has a significant drop in frequency during midday (14:00 to 19:00 UTC or 10:00 to 15:00 local time), whereas the frequency of category 1 spectra increases during this time period. Category 5 is not abundant at high solar irradiance and typically peaks in the morning.

Figure 10 shows the relative occurrence of the top five categories versus the photochemical age of their air masses. The fraction of spectra placed in category 1 increased with age and there is a decreasing trend for category 2 spectra. Since category 1 has a significant peak at $m / z 44$, this could indicate processing of the organic material detected in category 2 spectra to form more oxidized organic material. Alternatively, the increase in relative occurrence of category 1 spectra may be due to condensation of oxidized material from a different source. It must be noted that the sampled air masses probably originated from or passed over different source regions (Fig. 8), so the relative contribution of each category as a function of photochemical age is not necessarily indicative of changes to the aerosol composition as urban air ages. However, categories 1 and 2 tend to both be abundant when winds are from the direction of major urban areas. Furthermore, the relative peak intensity at $m / z 44$ increased over time in chamber studies of secondary organic aerosol formation (Alfarra et al., 2006), which is indicative of further oxidation during aging and consistent with the field data. The distributions shown in Fig. 10 for categories 3-5

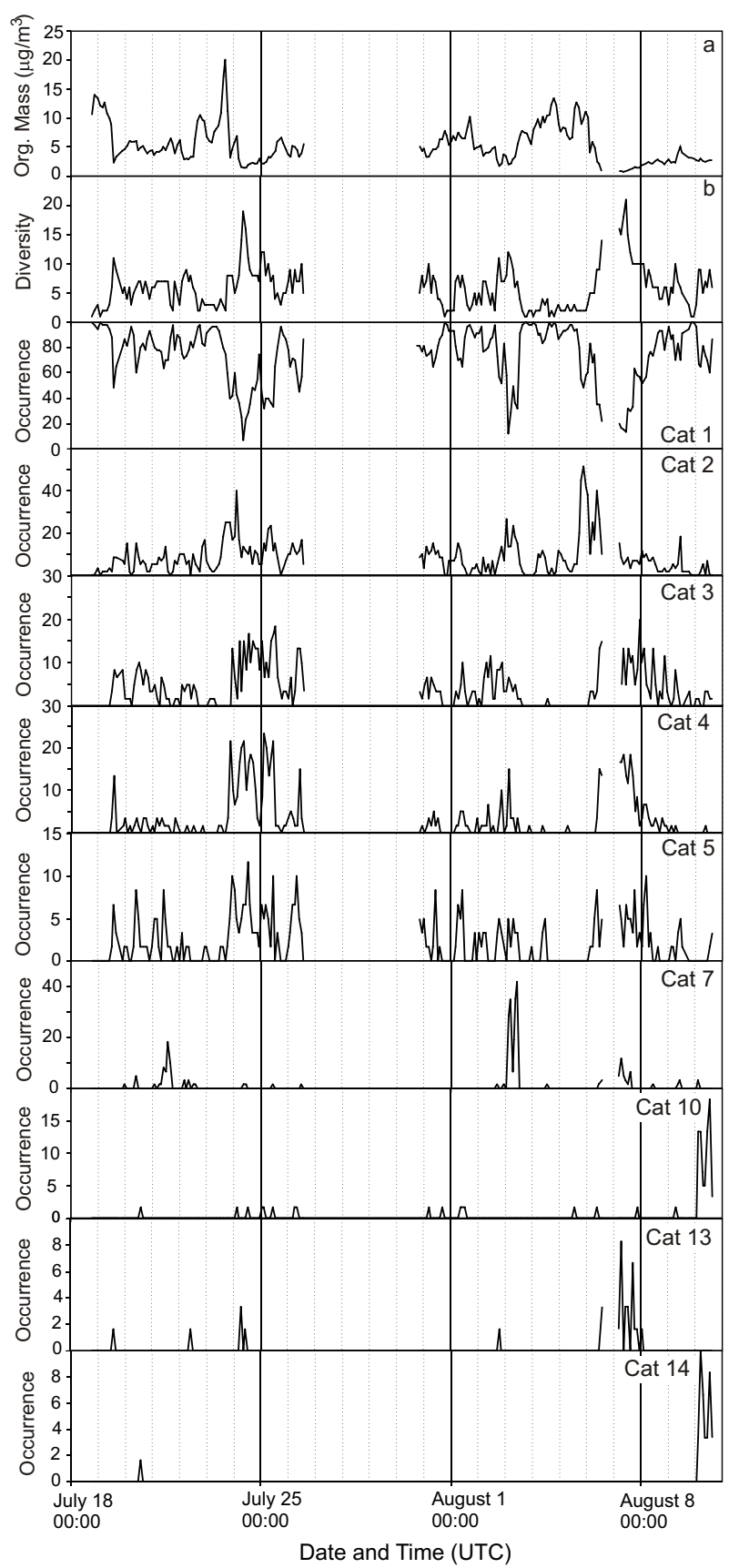

Fig. 7. Time series of the aerosol organic mass loading (a), the diversity (b), and the relative occurrence (\%) of the top 5 and other prominent categories.

are broad, yet tend to be relatively more important in younger air masses. Since the photochemical age is determined from anthropogenic VOCs originating from source regions in the west or southwest, only a weak correspondence with the degree of oxidation for categories $3-5$, which mainly occur during times with northerly winds, can be expected. The low correlation with photochemical age in Fig. 10 is therefore 


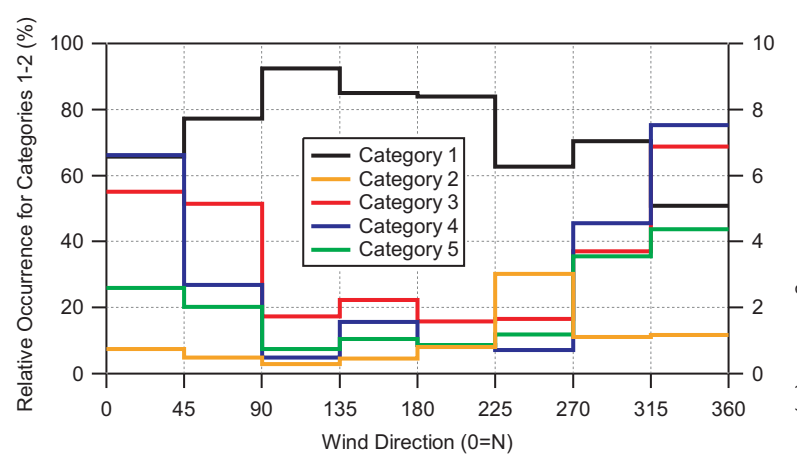

Fig. 8. Relative occurrence for categories 1 through 5 as a function of wind direction sorted for wind speeds greater than $4 \mathrm{~m} / \mathrm{s}$.
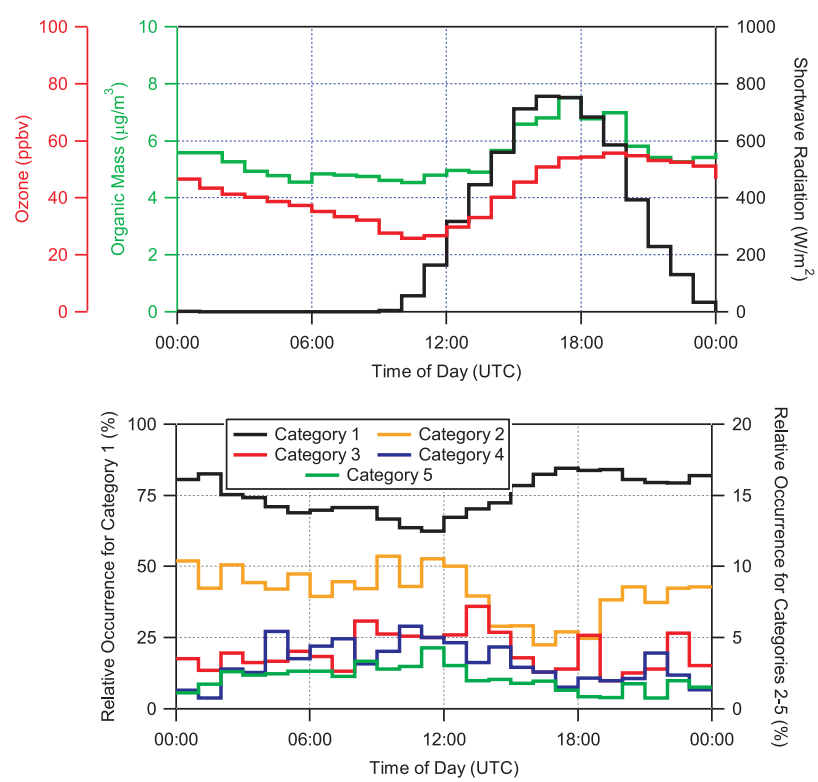

Fig. 9. Relative occurrence of particulate organic matter (top panel in green), ozone (top panel in red), and shortwave radiation (top panel in black) for a mean day averaged over the whole sampling period. Relative occurrence for categories 1 through 5 as a function of time of day (bottom panel).

consistent with the particulate organic matter in categories 3-5 being comprised of only minor contributions from anthropogenic precursors that have been oxidized during transport and aging.

\subsection{Correlations of categories $1-5$ with gas phase species}

The occurrence of categories 1 through 5 is shown as a function of time in Fig. 11 for 25-26 July, the time period when winds were from the north and the ship was sailing off the coast of Maine (detailed ship track and wind directions for this time period are given in Fig. 13a of de Gouw et al., 2005). At this time, the synoptic climate classification for

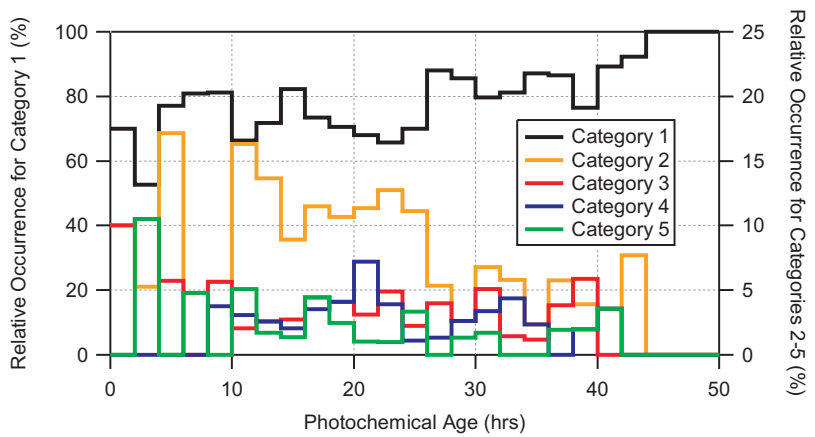

Fig. 10. Relative occurrence for categories 1 through 5 as a function of photochemical age.

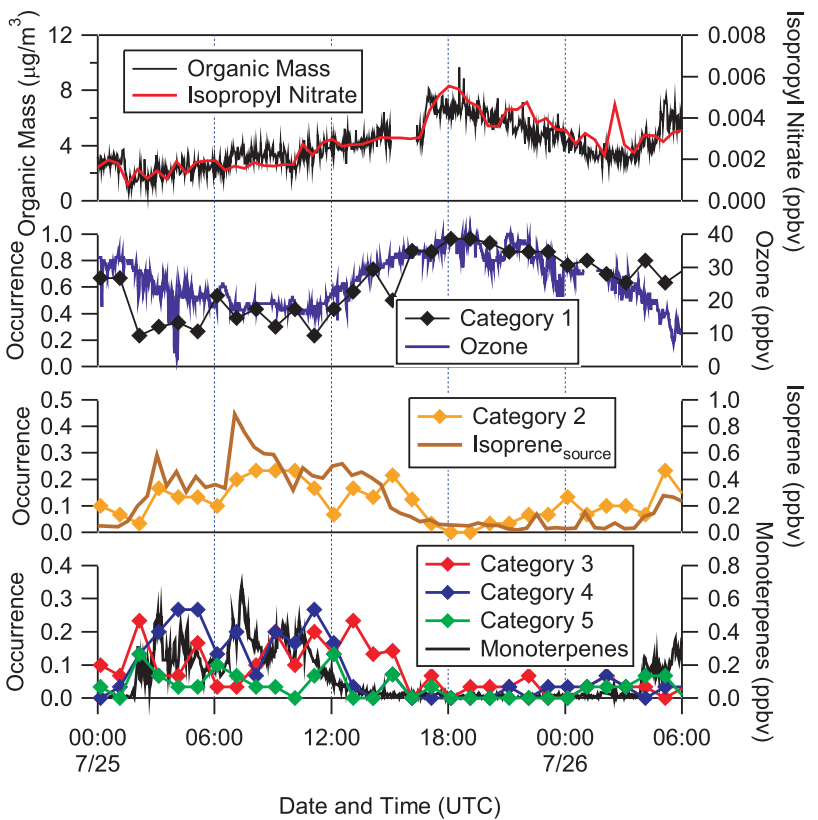

Fig. 11. Organic aerosol mass, isopropyl nitrate (a secondary anthropogenic volatile organic compound or VOC), ozone (from both biogenic and anthropogenic hydrocarbons), isoprene source (from de Gouw et al., 2005) and monoterpenes (biogenic VOCs), and the relative occurrence of categories 1 through 5 when the ship was sailing off the coast of Maine.

the region was a Canadian High, characterized by northerly or northwesterly winds from over Canada (Keim et al., 2005 ) with relatively high monoterpene emissions, moderate isoprene emissions, and low anthropogenic emissions (see Fig. 1). Biogenic organic aerosols were previously reported to be present during these conditions (Slater et al., 2002). Also shown are the organic mass loadings as well as the concentrations of ozone and selected volatile organic compounds (VOCs): isopropyl nitrate, isoprene from the source, and the sum of all the monoterpenes. As discussed by de Gouw et al. (2005) and shown in the top panel of Fig. 11, 
the organic mass during this study is correlated with a secondary anthropogenic species (isopropyl nitrate), despite the relatively high concentrations of isoprene and monoterpenes. For this time period, category 1 exhibits a distinct correlation with ozone. Indeed, $93 \%$ of the spectra when ozone concentrations are above $75 \mathrm{ppbv}$ are placed in category 1 and $6 \%$ are placed in category 2 . This is consistent with the relative contribution of $m / z 44$ to the total organic mass correlating with the fraction of calculated mass corresponding to secondary anthropogenic processes (de Gouw et al., 2005), which refer to reactions involving either biogenic or anthropogenic VOCs with secondary anthropogenic oxidants (ozone or nitrate radical) or with hydroxyl radical in the presence of high nitrogen oxide concentrations. Although the concentrations of monoterpenes and isoprene (shown in Fig. 5b of de Gouw et al., 2003) declined during the morning on 25 July (1000 to $14: 00$ UTC or 6:00 to 12:00 local time), the isoprene source concentrations remained high for several hours, characteristic of an increased loss rate of the monoterpenes and isoprene from photochemistry as the air passed over the water to the ship rather than decreasing emissions or a change of air mass, as can be seen from Fig. 13a of de Gouw et al. (2005) showing the ship track and wind direction during this sampling period. Category 4 and to a lesser degree categories 3 and 5 correlate with the monoterpenes, which is consistent with their spectral similarities with $\alpha$-pinene oxidation products as shown in Fig. 5. Whereas the rise of category 3 is simultaneous with the rise of the monoterpenes, its decline is delayed, which might be indicative of category 3 consisting of more oxidized, longer-lived monoterpene oxidation products that become relatively more abundant than category 4 and 5 species with increasing exposure to sunlight. Category 2 correlates better with the isoprene source concentrations, corroborating its characterization as isoprene oxidation products. Note that the isoprene source term is determined from the first generation oxidation products (methacrolein and methyl vinyl ketone). Including the second generation products as well as the first generation monoterpene products (such as pinonaldehyde) might show other trends. Shipboard measurements from 10:00 to 15:00 UTC indicate that the surface winds were from the same direction after sunrise, the wind speeds were approximately 5 knots, the ship moved much more slowly, and its track roughly paralleled the coast where the emissions were relatively constant. Hence, the time since emission for the air mass sampled from 10:00 to 15:00 UTC was approximately $6 \mathrm{~h}$. Therefore, the air sampled had left the coast during the night and was exposed to increasing levels of sunlight as the day progressed. Considering the quite constant wind direction, the increase of the organic mass and the rise of category 1 at 12:00 UTC are rather due to enhanced gasto-particle conversion with the onset of solar illumination than with a change of air mass source region, implying that from 12:00 to 15:00 UTC the particulate organic mass represented by category 1 could have biogenic sources. Minor levels of primary anthropogenic contributions are confirmed by the toluene gas phase concentration (shown in Fig. 5a of de Gouw et al., 2003) which was less than $0.2 \mathrm{ppbv}$ prior to 12:00 UTC and further declined when category 1 started to rise at 12:00 UTC. The correlations between the various biogenic gas phase species and categories 2-5 are strong during the time period depicted in Fig. 11 when the anthropogenic VOC concentrations were relatively low (iso-propyl nitrate $<6$ pptv and toluene $<0.2$ ppbv compared with plume values that are 5 times higher, see de Gouw et al., 2003, 2005). These trends (especially those with isoprene) are not as clear in other air masses due to the increased abundance of category 1 spectra as well as anthropogenic VOCs.

The findings shown here indicate that some of the organic material originated from biogenic species that may have been oxidized in the presence of anthropogenic pollution via either ozone, hydroxyl radicals, or nitrate radicals in the presence of nitrogen oxides. Categories 2-5 appear to be characteristic of biogenic secondary organic aerosols (Figs. 5 and 6) and their occurrence is correlated with biogenic gas phase species (Fig. 11). Categories 2-5 are not as oxidized as category 1 spectra (Fig. 3) and they decrease in occurrence during the middle of the day when category 1 was prominent (Fig. 9). The lack of correlation for category 1 with biogenic species does not preclude its organic material from being biogenic. Indeed, during 23 July from 15:30 to 18:00 UTC (11:30 to 14:00 local time) when $60-70 \%$ of the ozone is attributed to biogenic hydrocarbons as determined from the peroxycarboxylic nitric anhydrides (Williams et al., 1997; Marchewka et al., 2006), 75\% of the AMS spectra are placed in category 1 and $25 \%$ are placed in category 2 . On the basis of the evidence gathered in this study - comparison with reference spectra, delta analysis, incidence as a function of wind direction, and correlation with gas phase species - category 1 cannot be conclusively assigned to either biogenic or anthropogenic particulate organic matter. Rather, it might contain anthropogenic and biogenic contributions that are not distinguished with the stopping condition used in the cluster analysis. Aerosol processing leading to similar oxidation products for anthropogenic and biogenic precursors or strong fragmentation in the mass spectrometer might be reasons for high spectral similarities between anthropogenic and biogenic oxidation products. A high biogenic contribution to category 1 would be in accordance with radiocarbon measurements which show that modern carbon (rather than carbon from fossil fuel) is prevalent in atmospheric aerosols in a variety of urban areas in the U. S. (Klinedinst and Currie, 1999; Lemire et al., 2002; Lewis et al., 2004; E. Edgerton, personal communication) and around the world (Shibata et al., 2004; Szidat et al., 2004).

\subsection{Calculated biogenic organic mass from categories 2-5}

Assuming all of the organic mass in categories $2-5$ is due to biogenic species, the amount of biogenic organic mass can 


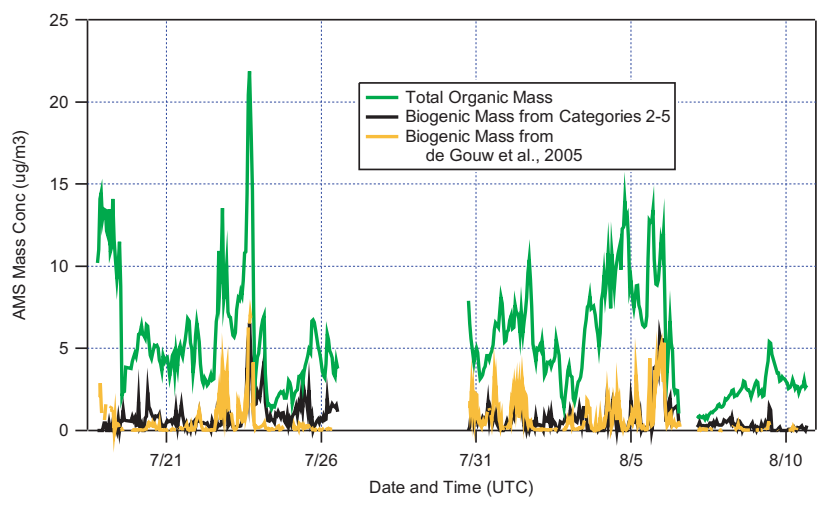

Fig. 12. Time trends of the total organic mass (green), the biogenic mass calculated from the mass in categories 2-5 (black), and the biogenic mass calculated from the biogenic fraction of the organic mass determined using the isoprene source concentrations by de Gouw et al., 2005 (yellow).

be calculated by an hourly average of the mass in those categories. On an hourly basis the total organic mass from spectra in categories $2-5$ was divided by the total organic mass in all categories (the fraction of organic mass in categories 2-5) and multiplied by the average organic mass. The calculated biogenic mass from the spectra is shown in Fig. 12 along with the biogenic mass determined from the fraction of organic mass attributed to biogenic processes based on the isoprene source concentrations (de Gouw et al., 2005). The agreement in the calculated biogenic mass is quite good for the second part of the study and during high mass loading periods. During the time period off the coast of Maine, the biogenic mass from the categories is significantly higher than that from the gas phase parameterization likely because monoterpenes were not included. Because category 1 is the most abundant category during the campaign, an accurate quantification of the contribution of biogenic species to the organic aerosol mass strongly depends on the estimated biogenic contribution to category 1 . If it was significant, the biogenic mass loadings shown in Fig. 12 would be a lower limit. On the other hand, a part of the mass especially in category 2 but also in categories 3-5 might be anthropogenic. The assumption that the mass in categories $2-5$ is totally biogenic might therefore lead to an overestimate of the biogenic organic mass at times when these categories are abundant. With this in mind, the contribution of biogenic species to the total organic mass by categories $2-5$ alone averaged $17 \%$ for the entire study and $10 \%$ (ranging from $0-50 \%$ ) when the total organic mass was more than $10 \mu \mathrm{g} / \mathrm{m}^{3}$. These values are comparable to $12 \%$ of the organic mass being attributed to biogenic sources for the whole dataset by the gas phase method (de Gouw et al., 2005). A scatter plot of biogenic mass calculated from the AMS data versus that from the gas parameterization is shown in Fig. 13. In order to make this plot, the gas phase data (biogenic mass calcula-

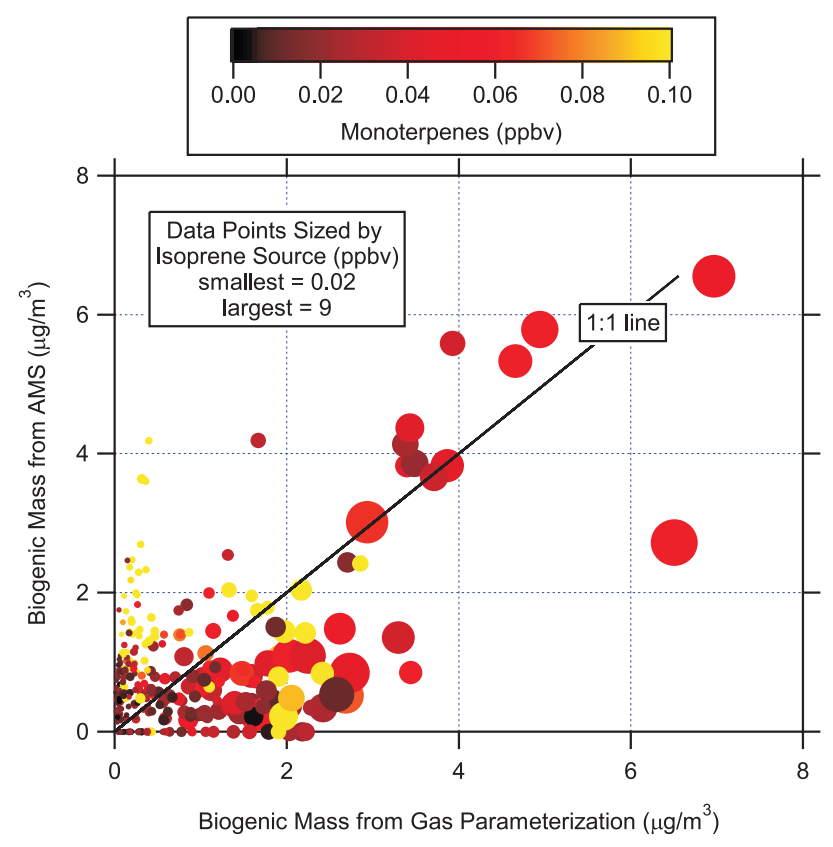

Fig. 13. A scatter plot of biogenic mass calculated from the AMS data (black trace in Fig. 12) versus that from the gas parameterization (yellow trace in Fig. 12, de Gouw et al., 2005).

tion from the gas phase parameterization and the isoprene source concentration) and the monoterpene concentrations were averaged to the AMS hourly average times. The correlation of all the data is quite weak (slope $=0.77, \mathrm{r}^{2}=0.33$ ). The time period depicted in Fig. 11 is represented by the high monoterpene data (yellow points) above the 1:1 line, where the AMS calculation is larger than the gas parameterization. This is because the gas parameterization does not include monoterpene compounds whereas the AMS calculation apparently does. Data where the isoprene source concentrations are low may indicate either low original biogenic emissions or aged biogenic airmasses that have lost MVK and MACR in addition to isoprene. The data with high isoprene source concentrations $(>0.5 \mathrm{ppbv})$ and low monoterpene concentrations $(<0.08 \mathrm{ppbv})$ do appear to correlate better (slope $=0.78, \mathrm{r}^{2}=0.55$ ). A slope less than 1 may be an indication that there is some biogenic contribution to category 1 that is not included in the AMS biogenic mass calculation. Most of the highest biogenic mass calculations $\left(>4 \mu \mathrm{g} / \mathrm{m}^{3}\right)$ are comparable with the two methods whereas the lowest biogenic mass calculations differ by less than $4 \mu \mathrm{g} / \mathrm{m}^{3}$. Furthermore, the highest "biogenic" mass concentrations occurred for isoprene rather than monoterpene biogenic species.

\subsection{Categories with a large peak at $\mathrm{m} / \mathrm{z} 30$}

Mass spectrometer signals at $m / z 30$ and 46 can arise from many species, yet the most prevalent in atmospheric submicron particles are ammonium nitrate and organic nitrate. In 

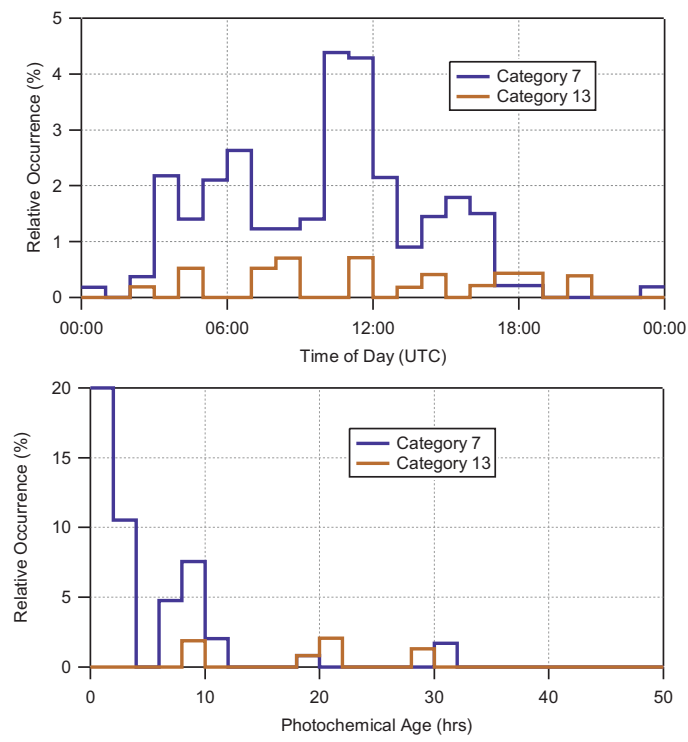

Fig. 14. Relative occurrence for categories 7 and 13 as a function of time of day (top panel) and photochemical age (bottom panel).

the NEAQS 2002 study, the average mole ratio of ammonium to sulphate was 1.7 from the AMS data and 1.5 from the PILS data, which indicates that on average not all of the sulphate was completely neutralized with ammonium. Since sulphate needs to be neutralized in order for significant amounts of ammonium nitrate to form, it is not surprising that the average nitrate levels for the entire study were low (Quinn and Bates, 2003; Brown et al., 2004; Bates et al., 2005). Mass $m / z 30$ could also arise from sodium nitrate formed in the atmosphere by reactions of nitrogen oxides with sea salt (e.g., Beichert and Finlayson-Pitts, 1996; Noble and Prather, 1997). Sodium nitrate has been detected in atmospheric particles with an AMS operating at $850^{\circ} \mathrm{C}$, which is a fairly high vaporization temperature necessary to detect sea salt (Allan et al., 2004b). Indeed, sodium nitrate was present during short periods of the NEAQS study when submicron sodium and nitrate were detected by the PILS instrument. However, the vaporization temperature of the AMS during NEAQS 2002 was $550^{\circ} \mathrm{C}$ (too low to efficiently vaporize sodium nitrate) and AMS nitrate concentrations were typically low during time periods when submicron sodium nitrate was present.

Both categories 7 and 13 contain large peaks at $m / z 30$ : in category 7 it is the dominant peak whereas it is the second most common peak after $m / z 44$ in category 13 (Fig. 3). The two categories are quite similar and their dot product is 0.76 ; without $\mathrm{m} / \mathrm{z} 44$ their dot product is 0.82 . Category 7 is mainly observed between 03:00 and 17:00 UTC (23:00 and 13:00 local time), with a significant peak between 10:00 and 12:00 UTC (top panel of Fig. 14). At this time (6:00 to 8:00 local), $\mathrm{NO}_{3}$ and $\mathrm{N}_{2} \mathrm{O}_{5}$ are depleted, $\mathrm{HNO}_{3}$ is at a morning minimum, $\mathrm{OH}$ is beginning to increase, and there are large concentrations of $\mathrm{NO}_{x}$ which can form $\mathrm{HNO}_{3}$ and organic nitrates (Brown et al., 2004). In contrast, the category 13 spectra are observed throughout the day (top panel of Fig. 14). Although there are less data points to consider, the category 7 spectra have a strong decreasing trend with photochemical age (bottom panel of Fig. 14) compared to the spectra in categories $1-5$ (Fig. 10). Furthermore, category 7 spectra represent over $30 \%$ of the freshest air masses sampled (ages $<4 \mathrm{~h}$ ). There are only 5 spectra from category 13 with corresponding gas phase data for calculating their photochemical ages; yet they are present in older air masses than the spectra in category 7 . Thus, the relative contributions of aerosol "nitrate" at $m / z, 30$ and oxidized organic material at $\mathrm{m} / \mathrm{z} 44$ in these categories appear to be attributable to differences in photochemical ages of the air masses sampled, with the older air masses (category 13 as well as all the top 5 categories) containing more oxidized organic material than the younger air masses (category 7 ).

The category 7 spectra appeared when both the AMS and PILS instruments detected significant nitrate levels, the submicron sodium mass was less than $0.2 \mu \mathrm{g} / \mathrm{m}^{3}$, and the organic mass was less than $5 \mu \mathrm{g} / \mathrm{m}^{3}$. For these spectra, the sulphate mass was always less than $4 \mu \mathrm{g} / \mathrm{m}^{3}$ and there was generally more ammonium than predicted if the sulphate was completely neutralized. Consequently, the spectra in category 7 are likely from particles containing ammonium nitrate.

The organic mass was less than $1 \mu \mathrm{g} / \mathrm{m}^{3}$ and the sulphate mass was nearly always less than $1 \mu \mathrm{g} / \mathrm{m}^{3}$ when category 13 spectra were present. For these spectra, the ammonium mass was below the detection limit $\left(0.7 \mu \mathrm{g} / \mathrm{m}^{3}\right)$, so the degree of sulphate neutralization could not be determined. Hence, the source of the signal at $m / z 30$ in the category 13 spectra is unclear.

In addition to being in categories 7 and $13, \mathrm{~m} / z 30$ is present at lower levels in the other top 15 categories (Table 3). Yet on average the sulphate in these particles was slightly acidic and ammonium nitrate did not usually form. The AMS nitrate did not correlate well overall with the PILS nitrate, probably because the PILS detected soluble nitrate (from ammonium and sodium nitrate) and the AMS detected volatile nitrate (from ammonium and organic nitrate). The ratios of $m / z 30$ to $m / z 46$ for the NEAQS 2002 data are typically greater than 5 , which is larger than the ratio from laboratory calibrations of ammonium nitrate particles (around 2). Ratios larger than 4 for these peaks have also been observed in oxidation studies where ammonium nitrate was not present (Alfarra et al., 2006; Bahreini et al., 2005). In fact, the reference spectra from isoprene and methacrolein oxidation products (Fig. 4b) have $m / z 30$ with an intensity that is similar to typical values in the top five categories (Fig. 3) and so $m / z, 30$ could have organic contributions or perhaps nitric acid was produced in the smog chamber studies. Therefore, $m / z 30$ in many of the NEAQS 2002 spectra could be due to organic nitrate (if relatively more $\mathrm{NO}^{+}$than 
$\mathrm{NO}_{2}^{+}$is formed compared to ammonium nitrate), an oxygenated organic fragment $\left(\mathrm{CH}_{2} \mathrm{O}^{+}\right)$, and/or an amine fragment $\left(\mathrm{CH}_{4} \mathrm{~N}^{+}\right)$. Unless a high resolution mass spectrometer is used to separate these isomers at $m / z 30$ (such as described by DeCarlo et al., 2006), the identification of the species contributing to this peak remains ambiguous.

3.8 Comparison of cluster analysis with single particle or ensemble data

While the method of generating clusters of mass spectra with single particle data or with ensemble data is similar, the principle goals of cluster analysis with these two types of data are different. From single particle data, the results of the cluster analysis are indicators of mixing state of individual particles. For example, spectra from individual particles measured in the stratosphere formed major clusters composed of primarily sulphate. Some were observed to also contain meteoritic material and trends in these particles were used to determine their source and approximate residence time (Murphy et al., 1998). In the troposphere, a wider variety of distinct particle types have been detected (e.g., Sullivan et al., 2006; Pekney et al., 2006; Ondov et al., 2006). However, most particles in the troposphere are composed of internally-mixed sulphate/carbonaceous material (Murphy et al., 2006). These particles are formed by coagulation, gas-to-particle partitioning, and particle-to-particle repartitioning (Marcolli et al., 2004) rather than co-emission since sulphate and organic particulate material do not originate from the same source.

In contrast, cluster analysis of ensemble data cannot infer the mixing state of individual particles; spectral signatures of groups of particles can be used to infer "mixing state" of air masses. In this study, most of the organic material in the air masses sampled had similar spectra features and, when combined with the gas-phase data, implied that aged air masses may be homogeneous. Furthermore, the AMS data are quantitative, thus providing an estimate of the biogenic organic mass based on spectra clusters.

For both types of data sets, the relative occurrence/frequency of various clusters must be weighted with the mass or number concentration to determine their relative importance. In this study, the largest classification of spectra (category 1) comprised $75 \%$ of the spectra sampled and represented a larger fraction of the organic mass (82\%). With the laser-based single particle instrumentation, quantification is difficult to achieve mainly due to irregular ionization efficiencies. Strides in single particle quantification may be possible with the new high-resolution, time-of-flight AMS instruments (DeCarlo et al., 2006; Canagaratna et al., 2006).

Cluster analysis works best on data sets with distinct features, affecting the results from single particle and ensemble data. Those with a continuum can place spectra in different classes yet the variations may be due to differences in relative peak intensities rather than purely different particle compositions (Middlebrook et al., 2003). Here we found that the rela- tive importance of $m / z 44$ affects the placement of ensemble spectra in different clusters. Nevertheless, cluster analysis has been useful in this application for separating out various spectral features that tended to be indicative of the air masses sampled.

3.9 Comparison of hierarchical clustering with other data analysis methods

Many mass spectra in the analyzed AMS dataset were very uniform with a strong peak at $m / z 44$ as the main feature. The remaining spectra exhibited considerable variation of spectral characteristics that seemed to be specific for different sources or aging processes. In a principal component analysis, such minor numbers of mass spectra could easily be missed, since this method is designed to capture the main variances of a dataset. Moreover, a principal component analysis per se is not able to extract characteristic spectra but produces factors that are not directly comparable with reference spectra. An alternative way of analyzing AMS data is their deconvolution based on mass spectral tracers as demonstrated by Zhang et al. (2005a). This method must anticipate the relevant peaks and might become inconvenient if a high number of tracers were required. In contrast to this technique, the cluster analysis neither needs a preselection of relevant peaks nor any additional information such as gas phase concentrations of correlated species or wind directions. The use of the dot product as a similarity criterion for clustering implies that the most intense peaks primarily determine the categorization and are therefore the common features of all spectra in a category. In the investigated dataset, peaks with $\mathrm{m} / \mathrm{z}$ below 50 dominate the organic mass signals. Since they are fragments of larger molecules and indicative of functional groups, they cannot be used to identify the presence of specific organic molecules. Nevertheless, clustering based on these low $m / z$ peaks was able to extract categories that match well the mass spectral signatures of monoterpene and isoprene oxidation products and identify spectra with contaminants. Thus, the clusters derived from the hierarchical cluster analysis can be employed to facilitate the further analysis of a dataset, either by comparing with other measurements and source identification or inspecting the representative spectra of each cluster and comparing with reference spectra. This technique may also be useful in probing the 'partly oxidised' mass spectra, frequently observed by the AMS when sampling regional emissions, that conform to neither the model "hydrocarbon-like" or "oxidized" organic aerosol defined by Zhang et al. (2005a).

In the present dataset, $75 \%$ of the spectra are assigned to one category without any further discrimination. To retrieve additional information regarding the behaviour within category 1 , the cluster analysis could be repeated with a stricter stopping condition leading to more categories. Repeating the cluster analysis with a whole set of stopping conditions might indeed be beneficial to elaborate specific features of 
the dataset. A prior knowledge of air mass history or possible reference spectra might help to optimize the stopping condition and thus increase the relevance and specificity of the categories. Alternatively, a dataset could be clustered around a database of references allowing a direct assignment of at least a part of the spectra. Since hierarchical cluster analysis does not resolve spectra of mixtures into their components but just categorizes them according to their dominant features, it needs air masses that show varying compositions as a function of time to retrieve different aerosol types. This condition was fulfilled for the present dataset collected on a mobile platform. Time series from urban studies where complex mixtures are continuously sampled might show less variation as a function of time. In this case, its ability to isolate different aerosol types will be limited. The categorization of each spectrum according to its dominant feature also sets a limitation on the ability of hierarchical cluster analysis to yield quantitative results. Clusters might represent mixtures of sources which can not be further taken apart. Nevertheless, the quantification of the biogenic aerosol fraction based on the occurrence of categories 2-5 gave a reasonable agreement with the biogenic fraction derived from correlations with gas phase species. Taken together, hierarchical cluster analysis allows to assess the spectral variability within an AMS dataset and can serve as a guide for further analysis. Application of hierarchical cluster analysis to further AMS datasets and comparison with other methods is needed to evaluate the potential of this technique more thoroughly.

\section{Conclusions}

Hierarchical cluster analysis was for the first time applied to an AMS dataset. Exclusion of peaks with inorganic contributions except for the nitrate peaks allowed us to focus on the organic aerosol fraction. The cluster analysis yielded a series of categories that are distinguishable with respect to their mass spectra and their occurrence as a function of time and wind direction. Furthermore, the spectral signatures of low $m / z$ peaks in the most common categories are similar to reference spectra from field campaigns or generated in laboratory chamber studies. On the basis of the combined information (spectral and trace gas correlations), category 2 contains contributions from isoprene oxidation products and the organic mass in categories 3 through 5 appears to be formed by oxidation of monoterpenes. Taken together, categories 2 through 5 represent up to $5 \mu \mathrm{g} / \mathrm{m}^{3}$ of biogenic organic aerosol mass, averaging $17 \%$ of the total organic mass for the entire study and only $10 \%$ of the total organic mass when the total organic mass is greater than $10 \mu \mathrm{g} / \mathrm{m}^{3}$. In contrast, the source of the organic mass in the category 1 spectra is unclear, since the spectra were placed in that category because they had a large signal at $m / z 44$, which is indicative of highly oxidized organic material irrespective of its origin.
This study demonstrates that hierarchical clustering is a useful tool to analyze the complex patterns of the organic peaks in bulk aerosol mass spectra from a field study.

Acknowledgements. This work was supported by the Swiss National Foundation under contract No. 200020-10365/1 and the NOAA Health of the Atmosphere program. We thank T. Peter for making this collaboration possible and the crew of the NOAA research vessel Ronald $\mathrm{H}$. Brown for their assistance during the 2002 NEAQS study. The aerosol group at NOAA PMEL headed by T. Bates and T. Quinn provided the inlet and helpful discussions about the data. Several people provided fruitful discussions about the data acquisition and analysis: M. Aldener, C. Brock, S. Brown, H. Coe, P. DeCarlo, E. Edgerton, C. Eubank, K. Hayden, P. Hudson, J. Jayne, J. Jimenez, J. Kimmel, J. Kroemer, J. Kroll, B. Matthew, P. Murphy, C. Simons, H. Stark, D. Sueper, Q. Zhang, and P. Ziemann. We appreciate receiving unpublished AMS reference spectra from R. Alfarra and S. Murphy. We are especially grateful to J. Allan for developing the AMS data analysis software, Matt Warshawsky for developing the original PALMS clustering algorithm, and D. Murphy for assistance with adapting it for the AMS data.

Edited by: Y. Rudich

\section{References}

Alfarra, M. R., Coe, H., Allan, J. D., Bower, K. N., Boudries, H., Canagaratna, M. R., Jimenez, J. L., Jayne, J. T., Garforth, A. A., Li, S. M., and Worsnop, D. R.: Characterization of urban and rural organic particulate in the Lower Fraser Valley using two Aerodyne aerosol mass spectrometers, Atmos. Environ., (Pacific 2001 special issue), 38, 5745-5758, 2004.

Alfarra, M. R., Paulsen, D., Gysel, M., Garforth, A. A., Dommen, J., Prevot, A. S. H., Worsnop, D. R., Baltensperger, U., and Coe, H.: A mass spectrometric study of secondary organic aerosols formed from the photooxidation of anthropogenic and biogenic precursors in a reaction chamber, Atmos. Chem. Phys., 6, 52795293, 2006,

http://www.atmos-chem-phys.net/6/5279/2006/.

Alfarra, M. R.: Insights into atmospheric organic aerosols using an aerosol mass spectrometer, $\mathrm{PhD}$ thesis under Prof. H. Coe, Univ. of Manchester, pp. 79-98 and 215-225, 2004.

Allan J. D., Alfarra, M. R., Bower, K. N., Williams, P. I., Gallagher, M. W., Jimenez, J. L., McDonald, A. G., Nemitz, E., Canagaratna, M. R., Jayne, J. T., Coe, H., and Worsnop, D. R.: Quantitative sampling using an Aerodyne aerosol mass spectrometer, 2. Measurements of fine particulate chemical composition in two U.K. cities, J. Geophys. Res., 108(D3), 4091, doi:10.1029/2002JD002359, 2003b.

Allan J. D., Jimenez, J. L., Williams, P. I., Alfarra, M. R., Bower, K. N., Jayne, J. T., Coe, H., and Worsnop, D. R.: Quantitative sampling using an Aerodyne aerosol mass spectrometer, 1. Techniques of data interpretation and error analysis, J. Geophys. Res., 108(D3), 4090, doi: 10.1029/2002JD002358, 2003a.

Allan, J. D., Bower, K. N., Coe, H., Boudries, H., Jayne, J. T., Canagaratna, M. R., Millet, D. B., Goldstein, A. H., Quinn, P. K., Weber, R. J., and Worsnop, D. R.: Submicron aerosol com- 
position at Trinidad Head, California, during ITCT 2K2: Its relationship with gas phase volatile organic carbon and assessment of instrument performance, J. Geophys. Res., 109, D23S24, doi:10.1029/2003JD004208, 2004b.

Allan, J. D., Delia, A. E., Coe, H., Bower, K. N., Alfarra, M. R., Jimenez, J. L., Middlebrook, A. M., Drewnick, F., Onasch, T. B., Canagaratna, M. R., Jayne, J. T., and Worsnop, D. R.: A generalised method for the extraction of chemically resolved mass spectra from Aerodyne aerosol mass spectrometer data, J. Aerosol Sci., 35(7), 909-922, doi: 10.1016/j.jaerosci.2004.02.007, 2004a.

Bahreini, R., Jimenez, J. L., Wang, J., Flagan, R. C., Seinfeld, J. H., Jayne, J. T., and Worsnop, D. R.: Aircraft-based aerosol size and composition measurements during ACE-Asia using an Aerodyne aerosol mass spectrometer, J. Geophys. Res., 108(D23), 8645, doi:10.1029/2002JD003226, 2003.

Bahreini, R., Keywood, M. D., Ng, N. L., Varutbangkul, V., Gao, S., Flagan, R. C., Seinfeld, J. H., Worsnop, D. R., and Jimenez, J. L.: Measurements of secondary organic aerosol from oxidation of cycloalkenes, terpenes, and $m$-xylene using an Aerodyne aerosol mass spectrometer, Environ. Sci. Technol., 39(15), 5674-5688, doi: 10.1021/es048061a, 2005.

Bates, T. S., Quinn, P. K., Coffman, D. J., Johnson, J. E., and Middlebrook, A. M.: Dominance of organic aerosols in the marine boundary layer over the Gulf of Maine during NEAQS 2002 and their role in aerosol light scattering, J. Geophys. Res., 110, D18202, doi: 10.1029/2005JD005797, 2005.

Beichert, P. and Finlayson-Pitts, B. J.: Knudsen cell studies of the uptake of gaseous $\mathrm{HNO}_{3}$ and other oxides of nitrogen on solid $\mathrm{NaCl}$ : The role of surface adsorbed water, J. Phys. Chem., 100, 15 218-15 228, 1996.

Blando, J. D. and Turpin, B. J.: Secondary organic aerosol formation in cloud and fog droplets: a literature evaluation of plausibility, Atmos. Environ., 34, 1623-1632, 2000.

Brown, S. S., Dibb, J. E., Stark, H., Aldener, M., Vozella, M., Whitlow, S., Williams, E. J., Lerner, B. M., Jakoubek, R., Middlebrook, A. M., DeGouw, J. A., Warneke, C., Goldan, P. D., Kuster, W. C, Angevine, W. M., Sueper, D. T., Quinn, P. K., Bates, T. S., Meagher, J. F., Fehsenfeld, F. C., and Ravishankara, A. R.: Nighttime removal of $\mathrm{NO}_{x}$ in the summer marine boundary layer, Geophys. Res. Lett., 31, L07108, doi: 10.1029/2004GL019412, 2004.

Canagaratna, M. R., Jayne, J. T., Ghertner, D. A., Herndon, S., Shi, Q., Jimenez, J. L., Silva, P. J., Williams, P., Lanni, T., Drewnick, F., Demerjian, K. L., Kolb, C. E., and Worsnop, D. R.: Chase studies of particulate emissions from in-use New York City vehicles, Aerosol Sci. Technol., 38, 555-573, 2004.

Canagaratna, M. R., Jayne, J. T., Jimenez, J. L., Allan, J. D., Alfarra, M. R., Zhang, Q., Onasch, T. B., Drewnick, F., Coe, H., Middlebrook, A., Delia, A., Williams, L. R., Trimborn, A. M., Northway, M. J., Kolb, C. E., Davidovits, P., and Worsnop, D. R.: Chemical and microphysical characterization of ambient aerosols with the Aerodyne aerosol mass spectrometer, Mass Spec. Rev., in press, 2006.

de Gouw, J. A., Goldan, P. D., Warneke, C., Kuster, W. C., Roberts, J. M., Marchewka, M., Bertman, S. B., Pszenny, A. A. P., and Keene, W. C.: Validation of proton transfer reaction-mass spectrometry (PTR-MS) measurements of gas-phase organic compounds in the atmosphere during the New England Air Quality
Study (NEAQS) in 2002, J. Geophys. Res., 108(D21), 4682, doi: 10.1029/2003JD003863, 2003.

de Gouw, J. A., Middlebrook, A. M., Warneke, C., Goldan, P. D., Kuster, W. C., Roberts, J. M., Fehsenfeld, F. C., Worsnop, D. R., Canagaratna, M. R., Pszenny, A. A. P., Keene, W. C., Marchewka, M., Bertman, S. B., and Bates, T. S.: Budget of organic carbon in a polluted atmosphere: Results from the New England Air Quality Study in 2002, J. Geophys. Res., 110, D16305, doi: 10.1029/2004JD005623, 2005.

DeCarlo, P. F., Kimmel, J. R., Trimborn, A., Northway, M. J., Jayne, J. T., Aiken, A. C., Gonin, M., Fuhrer, K., Horvath, T., Docherty, K. S., Worsnop, D. R., and Jimenez, J. L.: Field-deployable, high-resolution, time-of-flight aerosol mass spectrometer, Anal. Chem., 78, 8281-8289, doi:10.1021/ac061249n, 2006.

Goldan P. D., Kuster, W. C., Williams, E., Murphy, P. C., Fehsenfeld, F. C., and Meagher, J.: Nonmethane hydrocarbon and oxy hydrocarbon measurements during the 2002 New England Air Quality Study, J. Geophys. Res., 109, D21309, doi: 10.1029/2003JD004455, 2004.

Guenther, A., Karl, T., Harley, P., Wiedinmyer, C., Palmer, P. I., and Geron, C.: Estimates of global terrestrial isoprene emissions using MEGAN (Model of Emissions of Gases and Aerosols from Nature), Atmos. Chem. Phys., 6, 3181-3210, 2006, http://www.atmos-chem-phys.net/6/3181/2006/.

Jayne, J. T., Leard, D. C., Zhang, X., Davidovits, P., Smith, K. A., Kolb, C. E., and Worsnop D. R.: Development of an aerosol mass spectrometer for size and composition analysis of submicron particles, Aerosol Sci. Technol., 33, 49-70, 2000.

Jimenez, J. L., Jayne, J. T., Shi, Q., Kolb, C. E., Worsnop, D. R., Yourshaw, I., Seinfeld, J. H., Flagan, R. C., Zhang, X., Smith, K. A., Morris, J. W., and Davidovits, P.: Ambient aerosol sampling using the Aerodyne aerosol mass spectrometer, J. Geophys. Res., 108(D7), 8425, doi: 10.1029/2001JD001213, 2003.

Kalberer, M., Paulsen, D., Sax, M. Steinbacher, M., Dommen, J., Prevot, A. S. H., Fisseha, R., Weingartner, E., Frankevich, V., Zenobi, R., and Baltensperger, U.: Identification of Polymers as Major Components of Atmospheric Organic Aerosols, Science, 303, 1659-1662, 2004.

Kanakidou, M., Seinfeld, J. H., Pandis, S. N., Barnes, I., Dentener, F. J., Facchini, M. C., Van Dingenen, R., Ervens, B., Nenes, A., Nielsen, C. J., Swietlicki, E., Putaud, J. P., Balkanski, Y., Fuzzi, S., Horth, J., Moortgat, G. K., Winterhalter, R., Myhre, C. E. L., Tsigaridis, K., Vignati, E., Stephanou, E. G., and Wilson, J.: Organic aerosol and global climate modelling: a review, Atmos. Chem. Phys., 5, 1053-1123, 2005, http://www.atmos-chem-phys.net/5/1053/2005/.

Keim, B. D., Meeker, L. D., and Slater, J. F.: Manual synoptic climate classification for the East Coast of New England (USA) with an application to $\mathrm{PM}_{2.5}$ concentration, Climate Res., 28, 143-154, 2005

Klinedinst, D. B., and Currie, L. A.: Direct quantification of $\mathrm{PM}_{2.5}$ fossil and biomass carbon within the Northern Front Range Air Quality Study's domain, Environ. Sci. Technol., 33, 4146-4154, 1999.

Kroll, J. H., Ng, N. L., Murphy, S. M., Flagan, R. C., and Seinfeld, J. H.: Secondary organic aerosol formation from isoprene photooxidation under high- $\mathrm{NO}_{x}$ conditions, Geophys. Res. Lett., 32, L18808, doi: 10.1029/2005GL023637, 2005.

Kroll, J. H., Ng, N. L., Murphy, S. M., Flagan, R. C., and Sein- 
feld, J. H.: Secondary organic aerosol formation from isoprene photooxidation, Environ. Sci. Technol., 40(6), 1869-1877, doi: 10.1021/es0524301, 2006.

Lemire, K. R., Allen, D. T., Klouda, G. A., and Lewis, C. W.: Fine particulate matter source attribution for Southeast Texas using ${ }^{14} \mathrm{C} /{ }^{13} \mathrm{C}$ ratios, J. Geophys. Res., 107(D22), 4631, doi: 10.1029/2002JD002339, 2002.

Lewis, C. W., Klouda, G. A., and Ellenson, W. D.: Radiocarbon measurement of the biogenic contribution to summertime PM-2.5 ambient aerosol in Nashville, TN, Atmos. Environ., 38, 6053-6061, doi: 10.1016/j.atmosenv.2004.06.011, 2004.

Marchewka, M., Bertman, S. B., Roberts, J. M., Warneke, C., de Gouw, J., Kuster, W., Goldan, P., Williams, E., Lerner, B. M., Murphy, P., and Fehsenfeld, F. C.: Measurements of PANs during the New England Air Quality Study 2002, J. Geophys. Res., submitted, doi:10.1029/2006JD007569, 2006.

Marcolli, C., Luo, B. P., Peter, Th., and Wienhold, F. G.: Internal mixing of the organic aerosol by gas phase diffusion of semivolatile organic compounds, Atmos. Chem. Phys., 4, 25932599, 2004,

http://www.atmos-chem-phys.net/4/2593/2004/.

McLafferty, F. W. and Tureček, F.: Interpretation of mass spectra, University Science Books, pp. 91-95, Sausalito, CA, 1993.

Middlebrook, A. M., Murphy, D. M., Lee, S.-H., Thomson, D. S., Prather, K. A., Wenzel, R. J., Liu, D.-Y., Phares, D. J., Rhoads, K. P., Wexler, A. S., Johnston, M. V., Jimenez, J. L., Jayne, J. T., Worsnop, D. R., Yourshaw, I., Seinfeld, J. H., and Flagan, R. C.: A comparison of particle mass spectrometers during the 1999 Atlanta Supersite Project, J. Geophys. Res., 108(D7), 8424, doi:10.1029/2001JD000660, 2003.

Murphy, D. M., Cziczo, D. J., Froyd, K. D., Hudson, P. K., Matthew, B. M., Middlebrook, A. M., Peltier, R. E., Sullivan, A., Thomson, D. S., and Weber, R. J.: Single-particle mass spectrometry of tropospheric aerosol particles, J. Geophys. Res., 111, D23S32, doi:10.1029/2006JD007340, 2006.

Murphy, D. M., Middlebrook, A. M., and Warshawsky M.: Cluster analysis of data from the particle analysis by laser mass spectrometry (PALMS) instrument, Aerosol Sci. Technol., 37, 382391, 2003.

Murphy, D. M., Thomson, D. S., and Mahoney, M. J.: In situ measurements of organics, meteoritic material, mercury, and other elements in aerosols at 5 to 19 kilometers, Science, 282, 16641669, 1998.

Noble, C. A. and Prather, K. A.: Real-time single particle monitoring of a relative increase in marine aerosol concentration during winter rainstorms, Geophys. Res. Lett., 24, 2753-2756, 1997.

Ondov, J. M., Buckley, T. J., Hopke, P. K., Ogulei, D., Parlange, M. B., Rogge, W. F., Squibb, K. S., Johnston, M. V., and Wexler, A. S.: Baltimore Supersite: Highly time- and size-resolved concentrations of urban $\mathrm{PM}_{2.5}$ and its constituents for resolution of sources and immune responses, Atmos. Environ., 40, Supp. 2, S224-S237, 2006.

Pekney, N. J., Davidson, C. I., Bein, K. J., Wexler, A. S., and Johnston, M. V.: Identification of sources of atmospheric PM at the Pittsburgh Supersite Part I: Single particle analysis and filterbased positive matrix factorization, Atmos. Environ., 40, Supp. 2, S411-S423, 2006.
Pöschl, U.: Atmospheric aerosols: Composition, transformation, climate and health effects, Angew. Chem. Int. Ed., 44, 75207540, doi:10.1002/anie.200501122, 2005.

Quinn, P. K. and Bates T. S.: North American, Asian, and Indian haze: Similar regional impacts on climate?, Geophys. Res. Lett., 30(11), 1555, doi: 10.1029/2003GL016934, 2003.

Schneider, J., Borrmann, S., Wollny, A. G., Bläsner, M., Mihalopoulos, N., Oikonomou, K., Sciare, J., Teller, A., Levin, Z., and Worsnop, D. R.: Online mass spectrometric aerosol measurements during the MINOS campaign (Crete, August 2001), Atmos. Chem. Phys., 4, 65-80, 2004, http://www.atmos-chem-phys.net/4/65/2004/.

Shibata, K., Endo, M., Yamamoto, N., Yoshinaga, J., Yanagisawa, Y., Endo, O., Goto, S., Yoneda, M., Shibata, Y., and Morita, M.: Temporal variation of radiocarbon concentration in airborne particulate matter in Tokyo, Radiocarbon, 46, 485-490, 2004.

Slater, J. F., Dibb, J. E., Keim, B. D., and Talbot, R. W.: Light extinction by fine atmospheric particles in the White Mountains region of New Hampshire and its relationship to air mass transport, Sci. Total Environ., 287, 221-239, 2002.

Sullivan, R. C., Guazzotti, S. A., Sodeman, D. A., and Prather, K. A.: Direct observations of the atmospheric processing of Asian mineral dust, Atmos. Chem. Phys. Discuss., 6, 4109-4170, 2006, http://www.atmos-chem-phys-discuss.net/6/4109/2006/.

Szidat, S., Jenk, T. M., Gäggeler, H. W., Synal, H.-A., Fisseha, R., Baltensperger, U., Kalberer, M., Samburova, V., Reimann, S., Kasper-Giebl, A., and Hajdas, I.: Radiocarbon $\left({ }^{14} \mathrm{C}\right)$-deduced biogenic and anthropogenic contributions to organic carbon (OC) of urban aerosols from Zürich, Switzerland, Atmos. Environ., 38, 4035-4044, doi: 10.1016/j.atmosenv.2004.03.066, 2004.

Turpin, B. J., Saxena, P., and Andrews E.: Measuring and simulating particulate organics in the atmosphere: problems and prospects, Atmos. Environ., 34, 2983-3013, 2000.

Williams, J., Roberts, J. M., Fehsenfeld, F. C., Bertman, S. B., Buhr, M. P., Goldan, P. D., Hübler, G., Kuster, W. C., Ryerson, T. B., Trainer, M., and Young, V.: Regional ozone from biogenic hydrocarbons deduced from airborne measurements of PAN, PPN, and MPAN, Geophys. Res. Lett., 24(9), 1099-1102, 1997.

Zappoli, S., Andracchio, A., Fuzzi, S., Facchini, M. C., Gelencsér, A., Kiss, G., Krivácsy, Z., Molnár, Á., Mészáros, E., Hansson, H.-C., Rosman, K., and Zebühr, Y.: Inorganic, organic and macromolecular components of fine aerosol in different areas of Europe in relation to their water solubility, Atmos. Environ, 33, 2733-2743, 1999.

Zhang, Q., Alfarra, M. R., Worsnop, D. R., Allan, J. D., Coe, H., Canagaratna, M. R., and Jimenez, J. L.: Deconvolution and quantification of hydrocarbon-like and oxygenated organic aerosols based on aerosol mass spectrometry, Environ. Sci. Technol., 39, 4938-4952, doi:10.1021/es0485681, 2005a, b.

Zhang, Q., Canagaratna, M. R., Jayne, J. T., Worsnop, D. R., and Jimenez, J. L.: Time- and size-resolved chemical composition of submicron particles in Pittsburgh: Implications for aerosol sources and processes, J. Geophys. Res., 110, D07S09, doi:10.1029/2004JD004649, 2005b. 